\title{
MAUK'A PANTEÓN, RECONSTRUYENDO LA HISTORIA ${ }^{\left({ }^{*}\right.}$
}

\author{
MAUK'A PANTHEON, RECONSTRUCTING HISTORY
}

\author{
ANLI CHALCO SALAS ${ }^{(\star x)}$ \\ Fecha de recepción: 25 mayo de 2015 \\ Fecha de aprobación: 06 de junio de 2015
}

\section{RESUMEN}

En el distrito de Pisac, en el cerro Mama Ñusta, se evidenció un complejo sistema de almacenamiento o qollqas, ubicadas en el sector Mauk'a Panteón. Este se encuentra asociado a un sistema de andenería, una red de caminos (vinculados al camino principal del Antisuyu), dos grandes canales de riego muy bien planificados, la imponente montaña Mama Ñusta (símbolo de fertilidad y abundancia) y el sagrado río Willcamayu. Todos estos elementos en conjunto forman un paisaje natural y cultural de valor histórico, arqueológico, arquitectónico y simbólico, que en definitiva ayudó a comprender los diferentes eventos ocurridos desde los orígenes del distrito de Pisac. La ubicación de este sistema de almacenamiento resulta ser estratégico, por encontrarse a una considerable altura, emplazado sobre una ladera de fuerte pendiente y asentado sobre plataformas, donde las condiciones climáticas y la construcción de sistemas de ventilación fueron muy favorables para la conservación y almacenamiento de los productos excedentes en la época prehispánica. Teniendo en cuenta esta riqueza, por mucho tiempo invisibilizada, cubierta por la densa vegetación, que contribuye a su deterioro, con efectos muchas veces irreversibles, inicio con entusiasmo la difusión de la presente investigación.

\section{PALABRAS CLAVE}

Sistema de almacenamiento, qollqas, ventilación

\section{ABSTRACT}

In the district of Pisac, at Mama Nusta mountain, a complex storage system or qollqas was spotted, in the sector of Mauk'a Pantheon. It is linked to a terrace system, a network of roads (connected to the main road of the Antisuyu), two well planned irrigation channels, the imposing mountain Mama Ñusta (symbol of fertility and abundance) and the sacred river Willcamayu. All of these elements together set up a natural and cultural landscape of great historical, archaeological, architectural and symbolic value, which ultimately helped to understand the different events that occurred since the origins of the Pisac district. The location of this storage system proves to be strategic, them being at a considerable height, located on a steep hillside and set on platforms, where climatic conditions and ventilation systems were very favorable for the preservation and storage of surplus products in prehispanic times. With all this richness in mind, richness that has long been made invisible, covered by the dense vegetation, which contributes to its deterioration, with often irreversible effects, is that I start spreading this investigation enthusiastically.

\section{KEYWORDS}

Storage system, qollqas, ventilation

(*) El presente artículo forma parte de la tesis titulada "Prospección arqueológica en el cerro Nustapata - Pisac - Provincia Calca (Cusco)" desarrollada en el 2012 por la Bach. Anli Chalco Salas y el Bach. Edy Valencia Herrera, para optar al título profesional de Licenciado en Arqueología, con la asesoría y dirección del Dr. Félix Danilo Pallardel Moscoso.

${ }^{* *}$ Licenciada en Arqueología, egresada de la Universidad Nacional San Antonio Abab del Cusco, inscrita en el Colegio Profesional de Arqueólogos del Perú. Trabajó en proyectos de investigación arqueológica del Programa Qhapaq Ñan, en evaluaciones arqueológicas de inmuebles ubicados en el Centro Histórico del Cusco, así como en diversos monitoreos arqueológicos. Actualmente, viene concluyendo sus estudios de postgrado en la Universidad Nacional Mayor de San Marcos de Lima, en la Facultad de Ciencias Sociales, específicamente en la maestría en Gestión del Patrimonio Cultural. 
devenir Vol. 2, N³, ENERO- JUNIO 2015, PP. 79-98 - ESTUDIOS I ISSN 2312-7570

UNIVERSIDAD NACIONAL DE INGENIERÍ, LIMA

Figura 1. Plano de ubicación del sector Mauk'a Panteón en el Parque Arqueológico de Pisac PAP y distrito de Pisac.

Fuente. Ex Dirección Regional de

Cultura Cusco, 2005.

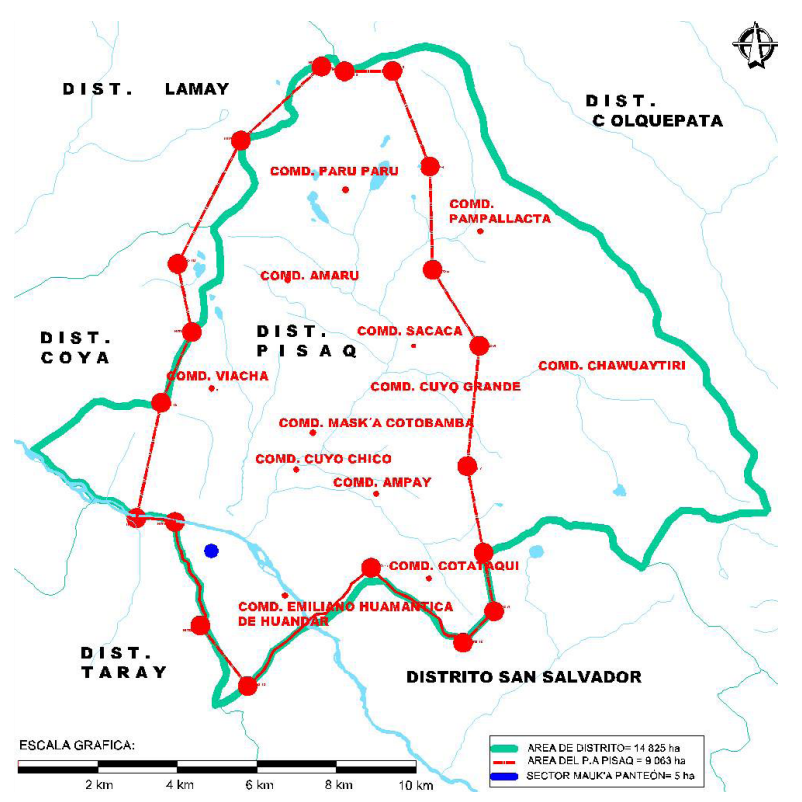

El Valle Sagrado de los Incas, en el departamento del Cusco, comprende un área de bastante trascendencia. El distrito de Pisac corresponde al inicio de este camino de tierra fértil y exuberante. La llegada del hombre al distrito de Pisac se dio 5000 a.C.; su presencia se encuentra perennizada en las pinturas rupestres de Machaycunas ${ }^{1}$, en el sector de Llamayuq K'uchu'2, perteneciente a la actual comunidad campesina de Chahuaytiri.

Paulatinamente, esta sociedad inicial preincaica se ubicó en las cumbres de los cerros más altos, a fin de tener el control absoluto sobre la microcuenca del distrito de Pisac. Ocuparon inicialmente lo que es hoy el sitio arqueológico de Pucara Pantillijlla, perteneciente a las comunidades campesinas de Cuyo Grande y Ayllu Ayamarca, actualmente conocida como Amaru, quienes dominaron los espacios ubicados a uno y otro margen del rio Willcamayu. Ambos lugares pertenecieron a la cuenca de los cuyos hasta la llegada de los incas, quienes redujeron a sus pobladores al piso del valle, a fin de construir grandes obras de ingeniería (sistemas de andenería, de almacenamiento o qollqas, red de caminos, etc.).

\section{Ubicación}

La presente investigación se realizó en el distrito de Pisac, perteneciente a la provincia de Calca y al departamento del Cusco (Figura 1), específicamente en el sector Mauk'a Panteón ${ }^{3}$ del cerro Mama Nusta, ubicado en la parte media del lado izquierdo de la montaña (Figura 2). Mediante la identificación, registro y análisis contextual de toda evidencia arqueológica prehispánica, en asociación con el material cultural mueble (fragmentos de cerámica y artefactos líticos), su finalidad es determinar la secuencia ocupacional de la zona.

\footnotetext{
1. Término quechua que hace referencia a un espacio de refugio bajo una roca (abrigos rocosos)

2. Término quechua que significa "rincón con figuras de llamas"

3. Término quechua que significa "cementerio viejo". De acuerdo a la investigación realizada, no sería un cementerio, sino que se trataría de un sistema de almacenaje o qollqas. La alusión al término cementerio se da por la presencia de una estructura funeraria o chullpa ubicada delante del Recinto 1 (R-1) (Figura 6), y el término viejo está referido al mal estado de conservación en el que se encuentra. Vale acotar que Mauk'a Panteón es un término usado por la actual población de Pisac; el nombre original del área se ha perdido en el tiempo.
} 


\section{Antecedentes}

Las investigaciones arqueológicas y documentación referentes a la función de los diferentes elementos arquitectónicos ubicados dentro del Parque Arqueológico de Pisac (PAP), entre ellos el sector Mauk'a Panteón, son muy escasas. Además, los estudios son muy superficiales y de carácter meramente descriptivo, como muestran los siguientes comentarios, distanciados por un periodo de casi 30 años, que dan cuenta de la persistencia del problema: "Ninguno de los cronistas ha mencionado esa localidad y hasta la fecha faltan estudios especializados..." (Gasparini \& Margolies, 1977, pp. 86-87).

Lamentablemente, la documentación de las restauraciones e intervenciones arqueológicas, efectuadas en los últimos 30 años, no se han publicado. Esta ausencia de información fundamental impide definiciones de mayor sustento respecto a las funciones inferidas por los elementos arquitectónico (Kaulike, Kondo, Kusada \& Zapata, 2003, p. 37).

Los datos etnohistóricos, históricos y arqueológicos refieren predominantemente al área monumental del Parque Arqueológico del distrito de Pisac. Es posible que el espacio del sector Mauk'a Panteón, en sus inicios, haya sido ocupado por un ayllu antiguo denominado Ayarmaca ${ }^{4}$, perteneciente al territorio de los cuyos ${ }^{5}$. Se llega a tal deducción por medio de la comparación arquitectónica de las evidencias halladas en dicho lugar:

Es interesante constatar que los Ayarmacas desempeñaron un rol importante en los inicios del Cusco, ellos sostuvieron prolongadas luchas contra los incas, y solo cuando surgió el Tahuantinsuyu quedaron definitivamente desbaratados y relegados al cargo de simples curacas locales, jefes de unos cuantos ayllus... (Rostworowski, 2004, p. 31)

Actualmente, en la comunidad de Amaru, se evidencian estructuras arquitectónicas como tumbas, recintos, andenes, caminos, etc., al igual que material cultural mueble (fragmentos de cerámica y artefactos líticos), correspondiente al estilo cerámico o periodo Killke, que data del año 1000 d.C., según la cronología planteada por Rowe en 1944:

Los datos de la prospección indican un importante crecimiento demográfico en el periodo Killke, cuando la cuenca de Cuyo estuvo dominada por varias grandes aldeas nucleares [...] situadas sobre cumbres de montaña a gran altura (más de $4000 \mathrm{msnm}$ ), la más grande de ellas fue Muyuch'urqu, una aldea de 6 hectáreas protegida por acantilados y muros defensivos [...]. Fue ubicada para que pudiera controlar el tráfico de las caravanas entre el valle del Vilcanota y las sierras bajas del Paucartambo, y habría dirigido un mosaico económico que incluía la producción agrícola y la ganadería. La prospección efectuada alrededor de Muyuch'urqu registró un estilo alfarero y una tradición mortuoria de torres funerarias que no se encuentra en áreas hacia el sur, con lo cual parece haber sido culturalmente distinto de los grupos que vivían en la cuenca del Cuzco... (Bauer, 2008, p. 169)

Por estudio comparativo, las características arquitectónicas constructivas de las torres funerarias referidas en la cita son las mismas que se registraron en el sector Mauk'a Panteón. En el último periodo de la época Killke, ocurrió un cambio en relación al desarrollo de los asentamientos, indicando que para entonces los incas habían empezado a ejercer dominio sobre el territorio de los cuyos, lo cual se refleja en la imposición de algunas caracterizas arquitectónicas agregadas:

\footnotetext{
4. Hoy conocido como comunidad campesina de Amaru, ubicada hacia la margen derecha del río Willcamayu, a $8 \mathrm{~km}$ de distancia del distrito de Pisac.

5. Actualmente existen dos lugares con esta denominación, que son las comunidades campesinas de Cuyo Grande y Cuyo Chico. Cuyo es un término quechua que significa movimiento, en referencia a la actividad geodinámica constante que hasta la actualidad presenta.
}

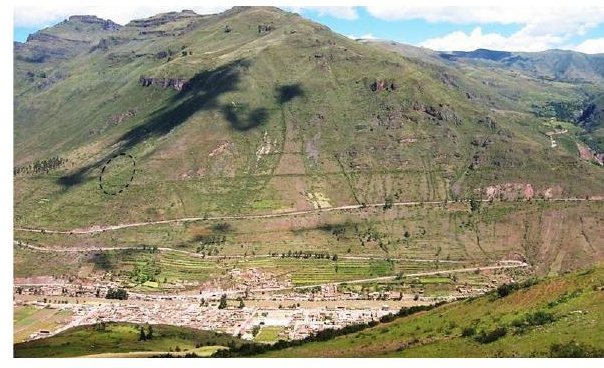

Figura 2. Vista panorámica del Cerro Mama Nusta y ubicación del sector Mauk'a Panteón (en líneas entrecortadas).

Fuente. Tesis de Licenciatura Anli Chalco, 2012. 
devenir Vol. 2, N³, ENERO- JUNIO 2015, PP. 79-98 - ESTUDIOS I ISSN 2312-7570

UNIVERSIDAD NACIONAL DE INGENIERÍ, LIMA

Tabla 1. Lista de las propiedades reales de los últimos Inkas.

Propiedades Reales de los 4 últimos soberanos Inkas- 1588

\begin{tabular}{cccc}
\hline Viracocha Inka & Pachakuteq Inka & Topa Inka Yupanqui & Huayna Qhapaq Inka \\
\hline Caquia Xaquigaguana. & Tambo & Chinchero & Yucay \\
Paucartica. & Pisac & Guayllabamba & Quispiguanca \\
& Patallacta & Urcos & Canabamba. \\
& Mollepongo & Callispuquio & Canchibamba \\
& Piccho & Xaquixaguana & Guaropampa \\
& Vitcos & Zurite & Pilcobamba \\
& Vilcabamba & & Pomaguanca \\
\hline
\end{tabular}

Fuente. Programa Qhapaq Ñan, Informe Arqueologico, 2011.

...La ubicación defensiva de su sitios y sus distintivos estilos alfareros y mortuorios, sugieren que la gente de esta cuenca no mantuvo contactos pacíficos con el Estado inca, en desarrollo durante buena parte del periodo Killke, el más grande asentamiento de esta época en el territorio de los cuyos es Pucara Pantillijlla, un lugar situado a 3950 msnm sobre una cadena montañosa, cruzando la cuenca desde Muyuch'urqu. Con más de 10 hectáreas [...] tiene mezcla de estructuras de piedras circulares y rectangulares... (Bauer, 2008, p. 169).

Desde los tiempos de Inca Roca, se mantuvieron muchos conflictos con este grupo étnico, que fue sometido poco a poco hasta la llegada del inca Pachakuteq, quien al cabo de muchas luchas terminó por integrar totalmente estas provincias a sus dominios (Tabla 1):

Una vez que la cuenca de Cuyo estuvo bien integrada en el centro inca, el asentamiento se desplazó al piso del valle del Vilcanota (900 metros hacia abajo), donde se le administró desde Pisaq, un lugar que fue hacienda particular de Pachacuti inca Yupanqui... (Bauer, 2008, p.170)

...por sus características constructivas no se duda que todo el complejo pertenezca a tiempos incaicos. Sobre la base de las evasivas menciones en las fuentes tempranas, se acepta, por lo general, que se trata de una sola obra de Pachacutec Inca, atribución fortalecida por estudios arquitectónicos comparativos con otros sitios asignados al mismo inca... (Kaulike, Kondo, Kusada, \& Zapata, 2003, p. 37)

Muchos de los vanos de acceso a las qollqas del sector Mauk'a Panteón fueron reforzados con piedra andesita y son de aparejo rectangular almohadillado, lo que confirmaría el estudio comparativo del tipo de arquitectura atribuida al Inca Pachacutec.

Las excavaciones del año 2000 efectuadas por Covey en Pucara Pantillijlla muestran que el área creció entre 1250 y 1350 d.C., cuando se construyeron muchos de los edificios rectangulares: "La cerámica inca imperial constituye un pequeño componente del conjunto excavado en Pucara Pantillijlla y el abandono de muchas de las estructuras residenciales del yacimiento entre 1300 y 1500 d.C. indica que su ocupación principal terminó antes del florecimiento del Periodo inca..." (Bauer, 2008, p. 70)

Algunos datos arqueológicos se aproximan un poco a la identificación del área de estudio, como los que brinda Pardo, quien menciona que "...el ayllu de Ayarmaca era de mayor extensión, comprendiendo los anexos de Chitapampa, Ccorao, Pumamarca, Quillahuata y Tticapcata; los ayllus Apumayta y Sañoc tenían como anexos a otros ayllus, que se extendían por toda la zona, hoy día ocupado por el pueblo y sus aledaños..." (Pardo, 1957, pp.351-354)

6. Chitapampa es un nombre que aún se conserva y pertenece a la actual comunidad campesina de Qorao, ubicada entre el distrito de Pisac y el Cusco, hacia la margen izquierda del rio Willcamayu. 
Por esta descripción, se sabe que el ayllu ayarmaca dominaba también los asentamientos ubicados hacia la margen izquierda del río Willcamayu, en el cual se ubica el sector Mauk'a Panteón.

En relación a los dos canales de riego que pasan por la parte superior e inferior del sector Mauk'a Panteón, Angles (2001) menciona que estaban en regular estado de conservación: "Hallamos también la obra de antiguos piseños, consistente en dos acueductos que estuvieron en uso hasta el primer tercio del siglo XX, más la andenería para fines agrícolas..." (p. 233). Actualmente esto no es así, ya que tramos de los muros de contención han colapsado.

El dato etnográfico coincide con esta fecha, la recopilación oral muestra que el canal inferior funcionó exactamente hasta el 21 de mayo de 1950, cuando aconteció un gran terremoto de 6,0 grados en la escala de Richter en la ciudad del Cusco. Este afectó a varios lugares, entre ellos al distrito de Pisac, y causó la destrucción de varios tramos de muro del canal de riego y de algunos recintos del sector Mauk'a Panteón.

Pardo también hace una descripción bastante certera de las evidencias arqueológicas ubicadas en del cerro Mama Ñusta y el sector Mauk'a Panteón:

Los monumentos de la margen izquierda del Vilcanota, están constituidos por lo general, por una serie de andenes ex profesamente construidos, con fines agrícolas [...] Probablemente, estaban regadas por el caudal de agua que viene por una extensísima acequia, captada más allá del pueblo de Huancalle, es decir, del riachuelo que se desliza desde Chitapampa, termina a dos kilómetros de Ppisacc y corre en sentido contrario al Vilcanota .En este sitio hallase un conjunto arqueológico de gran significación, pues, se trata de muchas viviendas, en buen estado. El conjunto es conocido por los aborígenes de la región bajo el nombre de "Maucka Panteón" (panteón viejo), por hallarse en este sitio entierros antiguos en huacas... (Pardo, 1957, pp. 351-354).

El termino vivienda mencionado por el autor estaría referido a las qollqas del sector Mauk'a Panteón, que, de acuerdo a la investigación efectuada, no serían viviendas, sino que cumplirían la función de almacén. Cabe señalar que en la parte inferior del sector Mauk'a Panteón se identificaron algunos recintos que sí cumplían la función de viviendas, por estar asociados a material cultural mueble (fragmentos de cerámica y artefactos líticos).

En el año 2003, Ronald Alan Covey realizó una investigación arqueológica para el grado de maestría titulada "The Vilcanota Valley (Perú): Inka State Formation and the Evolution of Imperial Strategies". De acuerdo a su informe, para el sector Mauk'a Panteón se hizo un levantamiento de 9 recintos (Figura 3). En el plano la ubicación del canal inferior pasa por la parte media del sector Mauk'a Panteón, cuando en realidad pasa por la inferior.

En los planos catastrales del distrito de Pisac, realizados por el ex Instituto Nacional de Cultura Cusco, en el año 1983 (Figura 4), y en 2005 por la ex Dirección Regional de Cultura Cusco (Figura 5), hoy Dirección Desconcentrada de Cultura Cusco, la información relativa a los elementos arquitectónicos ubicados en el sector Mauk'a Panteón presenta algunos vacíos en cuanto a la ubicación, emplazamiento y distribución de las evidencias.

En resumen, la función de este grupo de recintos ubicados en el sector Mauk'a Panteón no fue claramente identificada, quizás por la inaccesibilidad o poca visibilidad de las estructuras a causa de la densa vegetación.

\section{Metodología de Registro}

La metodología empleada fue de cambio y adaptación progresiva a las características del entorno, en pos de la mayor flexibilidad posible, sin que ello mengue la fiabilidad.

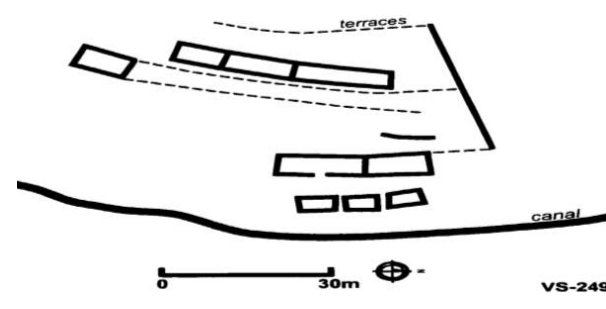

Figura 3. Levantamiento del sector Mauk'a Panteón.

Fuente. Covey, 2003.

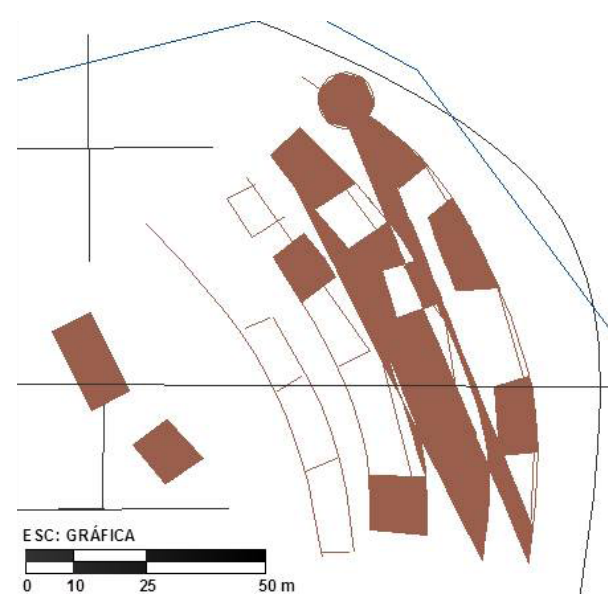

Figura 4. Levantamiento del sector Mauk'a Panteón.

Fuente. Ex INC, 1983.

Figura 5. Levantamiento del sector Mauk'a Panteón.

Fuente. Ex DRCC, 2005.

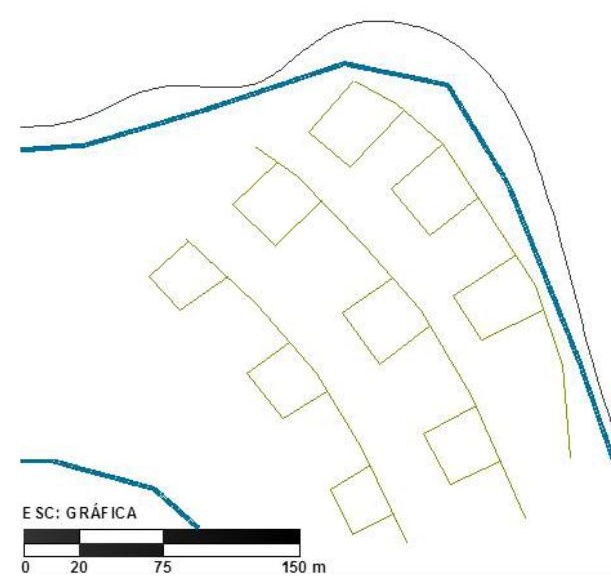


devenir Vol. 2, N³, ENERO- JUNIO 2015, PP. 79-98 - ESTUDIOS I ISSN 2312-7570

UNIVERSIDAD NACIONAL DE INGENIERÍ, LIMA

Figura 6. Plano arqueológico del Sector Mauk'a Panteón.

Fuente. Tesis de Licenciatura Anl Chalco, 2012.

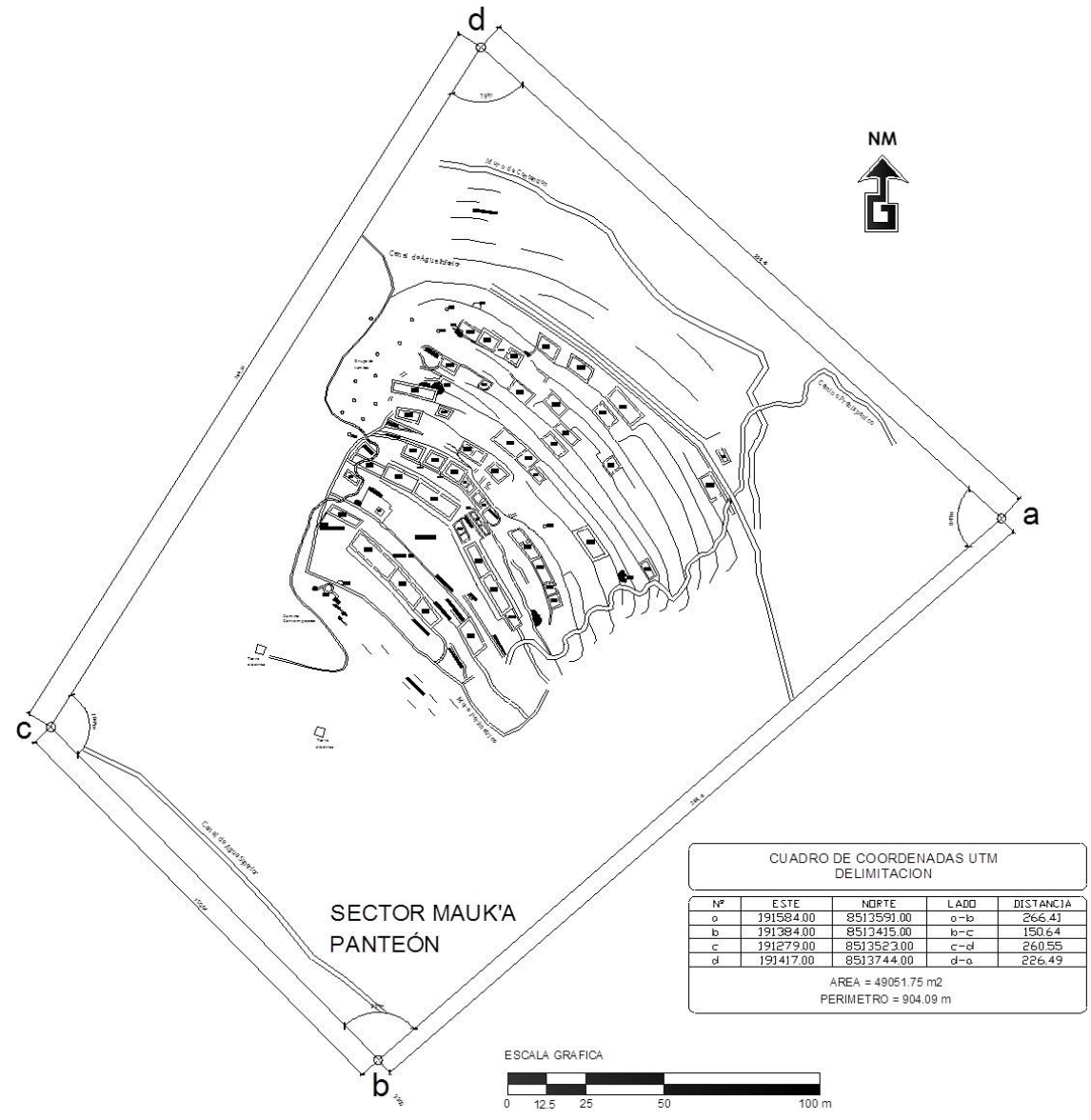

\section{Prospección Arqueológica Sistemática}

Actualmente la prospección más efectiva que permite la recolección certera de datos se realiza de forma sistemática "...empleando bien un sistema de red o bien una serie de recorridos equidistantes [...] Este método también facilita la situación exacta de los hallazgos, dado que siempre se conoce la posición exacta de cada uno..." (Renfrew \& Bahn, 1998, p. 72).

El recorrido se hizo a pie de forma longitudinal y transversal, avanzando pausadamente y cubriendo toda el área de estudio, tomando en cuenta que"...por lo general, una prospección superficial se lleva a cabo mediante recorridos longitudinales (transectos) [...] cuantos más transectos realices en una misma área, y más próximos estén entre sí, mejor será la cobertura de la prospección" (Domingo \& Heather, 2007, p. 102).

\section{Estrategias de Cobertura}

\section{La cobertura total}

Se dio en función a la evidencia arqueológica, en lugares cubiertos por la densa vegetación arbustiva, que obstaculizaba la visión y el desplazamiento.

\section{Estrategia de muestreo}

Dentro del sector Mauk'a Panteón, se ubicaron áreas de mayor probabilidad de datos resultantes. También se procedió a reprospectar el área de estudio en diversos momentos del año, por la variabilidad en el crecimiento de la vegetación. 


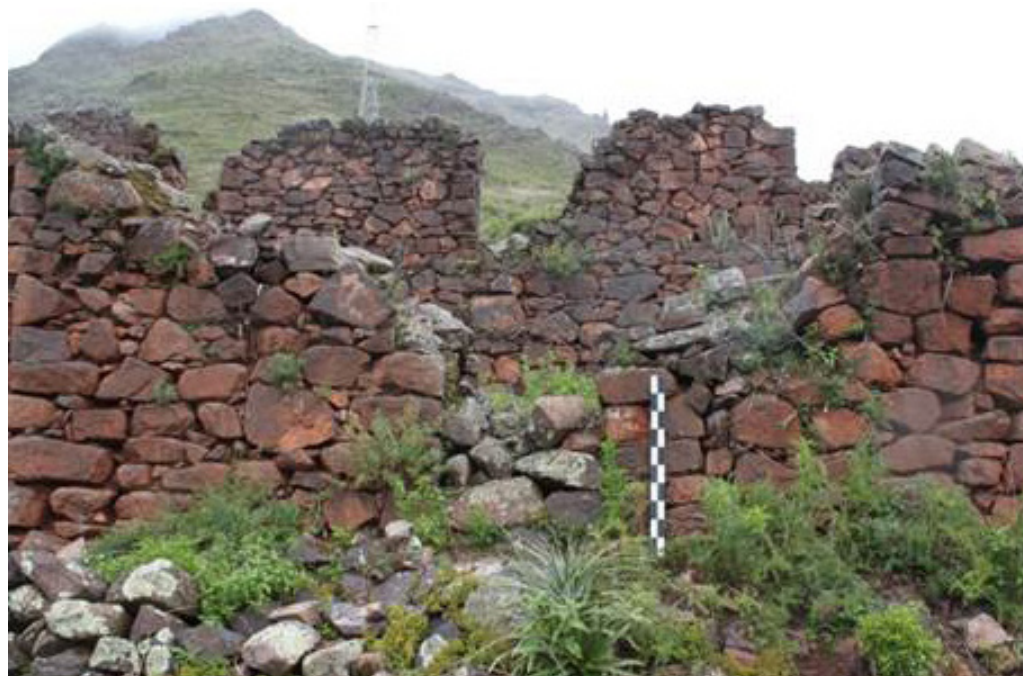

\section{Batida del terreno}

La recopilación de información fue determinada por la intensidad de la prospección, definida por el grado de detalle con que se inspeccionó la superficie: "...la cuestión fundamental radica en el intervalo que debe separar a los prospectores en el proceso de batida del territorio [...] es preciso tener presentes dos parámetros esenciales: el tipo y numero de movimientos y la distancia entre prospectores..." (García, 2005, p. 74).

Se lograron movimientos paralelos a intervalos de 2 metros, mediante los cuales se identificó y registró toda evidencia arqueológica.

\section{Prospección Arqueológica}

A pesar de la densa vegetación se logró registrar 49 recintos $^{7}$ (Tablas 2 y 3), en algunos casos a nivel de piso. Asimismo, se registraron el muro perimétrico, las tumbas, los espacios abiertos (tendales), las plataformas, las viviendas, los muros de contención, los caminos y los canales de riego (Figura 6).

\section{Análisis Morfológico}

Las qollqas en su mayoría presentan una inclinación del $4 \%$, son de aparejo rústico y en algunos casos los vanos de acceso son de aparejo ensamblado. El material constructivo es arenisca cuarzosa semicanteada de forma y tamaño irregular, unidas con mortero de barro y cuñas, mientras que las esquinas exteriores e interiores son de piedra canteada. En algunos casos se registró enlucido al interior de las qollqas. Se identificaron tres tipos de qollqas:

Tipo 1. De planta rectangular de dos niveles (Figura 7), presenta cuatro vanos de acceso de forma trapezoidal ubicadas en el muro frontal del primer nivel orientados al N-E, en relación directa a los vientos locales y cuatro vanos de acceso en el muro posterior del segundo nivel orientados al S-O (Figura 8), al igual que ventanas ubicadas en los muros laterales. Lo más probable es que tengan ductos de ventilación soterrados bajo el material acumulado (tierra y piedra), como sucede en los almacenes de Pinkuylluna en el Parque Arqueológico de Ollantaytambo. El segundo nivel forma una segunda plataforma delante del muro posterior, lo cual hace que los vanos tengan salida a este espacio (Figura 9). Este Tipo 1 es muy parecido a uno de los tipos de almacén
Figura 7. Recinto 01, vista del muro frontal y posterior.

Fuente. Tesis de Licenciatura Anli Chalco, 2012.

Figura 8. Plano de planta del recinto 01 (R-01), Tipo 01.

Fuente. Tesis de Licenciatura Anli Chalco, 2012.

7. En la presente investigación, el término recinto engloba tanto a qollqas como a viviendas (ambos términos están referidos al tipo de función que cumplía el recinto). 
devenir Vol. 2, N³, ENERO- JUNIO 2015, PP. 79-98 - EsTUDIOS I ISSN 2312-7570

UniverSIDAd NACIONAL DE INGENIERÍA, LIMA

Tabla 2 Especificaciones técnicas de los recintos

\begin{tabular}{|c|c|c|c|c|c|c|c|c|c|c|c|}
\hline \multicolumn{12}{|c|}{ Especificaciones técnicas - recintos } \\
\hline \multirow{3}{*}{ No } & \multicolumn{4}{|c|}{ Espacio geográfico } & \multicolumn{6}{|c|}{ Medidas/ metros } & \multirow{3}{*}{$\begin{array}{c}\text { Ancho } \\
\text { de } \\
\text { muro }\end{array}$} \\
\hline & \multirow{2}{*}{ Este } & \multirow{2}{*}{ Norte } & \multicolumn{2}{|c|}{ Largo } & \multicolumn{2}{|c|}{ Ancho } & \multicolumn{4}{|c|}{ Altura } & \\
\hline & & & MF* & MP & MLN & MLS & MF & MP & MLN & MLS & \\
\hline R-01 & 191384 & 8513578 & 17.60 & 17.40 & 6.20 & 5.90 & 3.20 & 5.35 & 2.95 & 3.50 & 0.80 \\
\hline $\mathrm{R}-02$ & 191392 & 8513568 & 12.30 & 12.20 & - & 5.80 & 2.90 & 2.50 & - & 1.80 & 0.80 \\
\hline R-03 & 191400 & 8513560 & 8.90 & 8.50 & - & 5.30 & 1.50 & 1.20 & - & 1.70 & 0.80 \\
\hline R-04 & 191373 & 8513592 & 11.00 & 10.70 & 3.40 & 3.50 & - & 0.80 & - & 1.10 & 0.60 \\
\hline R-05 & 191413 & 8513552 & 11.40 & 11.20 & 6.20 & 5.90 & - & 2.10 & 1.50 & 1.10 & 0.70 \\
\hline R-06 & 191375 & 8513604 & 5.30 & 5.50 & 2.80 & 2.60 & 0.30 & 0.30 & 0.30 & - & 0.60 \\
\hline R-07 & 191380 & 8513608 & 11.20 & 12.60 & 3.90 & 3.90 & 0.40 & 1.60 & - & - & 0.70 \\
\hline R-08 & 191392 & 8513604 & 11.00 & 10.90 & 5.50 & - & 1.20 & 1.90 & 0.90 & - & 0.80 \\
\hline R-09 & 191402 & 8513597 & 16.00 & 15.20 & 5.60 & 6.00 & 1.90 & 2.10 & 1.50 & 2.20 & 0.80 \\
\hline $\mathrm{R}-10$ & 191411 & 8513586 & 7.70 & 7.40 & 3.60 & 3.20 & 1.15 & 0.40 & 0.20 & 0.95 & 0.50 \\
\hline $\mathrm{R}-11$ & 191416 & 8513577 & 10.40 & 11.30 & 4.20 & - & 0.80 & - & - & - & 0.80 \\
\hline $\mathrm{R}-12$ & 191422 & 8513567 & 13.90 & 14.10 & 4.80 & 5.00 & 1.70 & 0.40 & 0.50 & 0.30 & 0.80 \\
\hline $\mathrm{R}-13$ & 191427 & 8513588 & 6.50 & 6.20 & - & 3.50 & - & 0.60 & - & 0.60 & 0.60 \\
\hline R-14 & 191395 & 8513613 & 6.60 & 6.00 & 4.90 & 5.20 & 2.50 & 2.00 & 0.85 & 2.00 & 0.70 \\
\hline $\mathrm{R}-15$ & 191402 & 8513609 & 6.00 & 6.00 & 5.20 & 5.30 & 2.80 & 1.30 & 1.50 & 1.50 & 0.70 \\
\hline $\mathrm{R}-16$ & 191409 & 8513605 & 6.80 & 7.00 & 5.20 & 5.30 & 1.90 & 2.20 & 0.40 & 2.30 & 0.70 \\
\hline $\mathrm{R}-17$ & 191413 & 8513601 & 5.40 & 4.60 & - & 3.20 & - & - & - & - & 0.60 \\
\hline $\mathrm{R}-18$ & 191417 & 8513596 & 6.80 & 6.60 & 3.40 & 3.30 & 1.00 & - & - & 1.00 & 0.60 \\
\hline R-19 & 191416 & 8513589 & 9.50 & 9.50 & 2.10 & 2.10 & 0.20 & 0.50 & 0.30 & - & 0.50 \\
\hline $\mathrm{R}-20$ & 191432 & 8513582 & 12.10 & 12.00 & 4.30 & 4.30 & 0.50 & 1.90 & - & 0.30 & 0.60 \\
\hline $\mathrm{R}-21$ & 191437 & 8513574 & 4.30 & - & 9.00 & 8.70 & 0.60 & - & - & 1.10 & 0.60 \\
\hline $\mathrm{R}-22$ & 191439 & 8513568 & 4.00 & 4.60 & - & 4.30 & 0.30 & 0.50 & - & 0.50 & 0.60 \\
\hline $\mathrm{R}-23$ & 191441 & 8513564 & 4.00 & 4.20 & - & 4.30 & 0.15 & 0.20 & - & - & 0.60 \\
\hline $\mathrm{R}-24$ & 191393 & 8513624 & 8.30 & 7.60 & 3.50 & 4.50 & 1.20 & 1.00 & 1.00 & 1.00 & 0.80 \\
\hline $\mathrm{R}-25$ & 191415 & 8513612 & 8.60 & 8.60 & 4.40 & 4.60 & - & - & 1.10 & - & 0.70 \\
\hline $\mathrm{R}-26$ & 191422 & 8513606 & 6.30 & 6.40 & 4.60 & 4.60 & 0.20 & 1.20 & - & 0.80 & 0.70 \\
\hline $\mathrm{R}-27$ & 191405 & 8513625 & 4.80 & 4.50 & 3.20 & 3.20 & 0.40 & 0.40 & 0.30 & 0.40 & 0.70 \\
\hline $\mathrm{R}-28$ & 191395 & 8513632 & 14.90 & 14.00 & 3.90 & 4.40 & 0.70 & 1.30 & 1.90 & 1.30 & 0.70 \\
\hline $\mathrm{R}-29$ & 191426 & 8513615 & 6.10 & 6.00 & 10.90 & 10.20 & 0.60 & 0.40 & 0.80 & 0.20 & 0.60 \\
\hline$R-30$ & 191432 & 8513610 & 5.70 & 5.90 & - & 6.00 & 0.30 & 0.10 & - & 0.20 & 0.60 \\
\hline $\mathrm{R}-31$ & 191434 & 8513604 & 6.00 & - & 3.00 & 1.40 & - & - & - & - & 0.60 \\
\hline$R-32$ & 191452 & 8513583 & 12.20 & 12.00 & 6.00 & 6.00 & 0.70 & 1.40 & - & - & 1.00 \\
\hline $\mathrm{R}-33$ & 191407 & 8513640 & 4.00 & 4.20 & 6.50 & 6.10 & 1.50 & 1.50 & 0.70 & 1.60 & 0.70 \\
\hline $\mathrm{R}-34$ & 191418 & 8513634 & 3.30 & 2.50 & 2.90 & 3.00 & 0.10 & - & - & - & 0.40 \\
\hline $\mathrm{R}-35$ & 191440 & 8513614 & 8.80 & 8.70 & 4.20 & 4.10 & 0.60 & 0.60 & 0.30 & 0.40 & 0.60 \\
\hline $\mathrm{R}-36$ & 191471 & 8513574 & 6.40 & 6.40 & 3.40 & 2.80 & 1.90 & 0.20 & 1.90 & 1.90 & 0.60 \\
\hline $\mathrm{R}-37$ & 191430 & 8513632 & 4.50 & 4.60 & 8.00 & 7.80 & 1.30 & 0.60 & 0.70 & 1.90 & 0.60 \\
\hline$R-38$ & 191445 & 8513618 & 8.90 & 8.90 & 3.60 & 3.80 & 1.00 & 2.00 & 0.50 & 0.40 & 0.60 \\
\hline $\mathrm{R}-39$ & 191413 & 8513652 & 7.20 & 7.20 & 4.20 & - & - & 0.30 & - & - & 0.50 \\
\hline $\mathrm{R}-40$ & 191420 & 8513648 & 5.10 & 5.60 & 7.00 & 6.70 & 1.10 & 1.20 & - & - & 0.70 \\
\hline R-41 & 191427 & 8513643 & 4.40 & 4.40 & 5.10 & 5.10 & 0.20 & 0.40 & 0.40 & 0.70 & 0.70 \\
\hline $\mathrm{R}-42$ & 191441 & 8513628 & 7.60 & 7.60 & 4.60 & 4.50 & 0.40 & 0.40 & 0.20 & - & 0.60 \\
\hline $\mathrm{R}-43$ & 191459 & 8513608 & 5.00 & 5.10 & 5.00 & 5.00 & 1.50 & 1.50 & - & - & 0.50 \\
\hline$R-44$ & 191457 & 8513625 & 4.80 & 4.80 & 8.20 & 8.80 & 1.80 & 0.30 & 0.40 & 0.50 & 0.60 \\
\hline$R-45$ & 191438 & 8513647 & 8.00 & 8.00 & 5.20 & 5.90 & 0.30 & 0.80 & 0.10 & 0.20 & 0.70 \\
\hline$R-46$ & 191449 & 8513639 & 9.00 & 8.40 & 5.20 & 5.40 & - & 0.40 & - & 0.25 & 0.70 \\
\hline$R-47$ & 191463 & 8513627 & 13.00 & 12.70 & 5.80 & 5.80 & 0.50 & 1.60 & 0.60 & 1.00 & 0.70 \\
\hline$R-48$ & 191491 & 8513601 & 5.40 & 5.00 & 8.70 & 8.90 & 1.80 & 0.20 & 1.10 & 1.90 & 0.80 \\
\hline$R-49$ & 191495 & 8513611 & 5.00 & 5.00 & 2.80 & 2.60 & 1.40 & 0.70 & 0.60 & 0.20 & 0.60 \\
\hline T-03 & 191385 & 8513593 & 2.50 & 2.60 & 1.90 & 1.80 & 1.70 & 0.70 & 1.70 & 0.30 & 0.60 \\
\hline
\end{tabular}


Tabla 3. Ficha de registro de los elementos arquitectónicos integrados a los recintos.

\begin{tabular}{|c|c|c|c|c|c|c|c|c|c|c|c|c|c|c|c|c|}
\hline \multicolumn{17}{|c|}{ Registro de los elementos arquitectónicos integrados } \\
\hline \multirow[b]{2}{*}{$\begin{array}{l}\text { No re- } \\
\text { cinto }\end{array}$} & \multirow[b]{2}{*}{ Muro } & \multicolumn{5}{|c|}{ Vano de acceso /m } & \multicolumn{5}{|c|}{ Ventana /m } & \multicolumn{5}{|c|}{ Ducto ventilación /m } \\
\hline & & No & $\begin{array}{l}\text { Espe- } \\
\text { sor }\end{array}$ & $\begin{array}{c}\text { Ancho } \\
\text { Um- } \\
\text { bral }\end{array}$ & $\begin{array}{l}\text { Ancho } \\
\text { Dintel }\end{array}$ & Altura & No & $\begin{array}{l}\text { Espe- } \\
\text { sor }\end{array}$ & $\begin{array}{c}\text { Ancho } \\
\text { Um- } \\
\text { bral }\end{array}$ & $\begin{array}{l}\text { Ancho } \\
\text { Dintel }\end{array}$ & Altura & No & $\begin{array}{l}\text { Espe- } \\
\text { sor }\end{array}$ & $\begin{array}{c}\text { Ancho } \\
\text { Um- } \\
\text { bral }\end{array}$ & $\begin{array}{l}\text { Ancho } \\
\text { Dintel }\end{array}$ & Altura \\
\hline \multirow{10}{*}{1} & \multirow{4}{*}{ MF } & 1 & 0.80 & 1.00 & - & 2.60 & 1 & 0.80 & 0.50 & 0.45 & 0.70 & - & - & - & - & - \\
\hline & & 2 & 0.80 & 0.90 & - & 1.00 & 2 & 0.80 & 0.50 & 0.50 & 0.45 & - & - & - & - & - \\
\hline & & 3 & 0.80 & 0.70 & - & 2.00 & 3 & 0.80 & 0.55 & - & 0.20 & - & - & - & - & - \\
\hline & & 4 & 0.80 & 0.75 & - & 1.60 & - & - & - & - & - & - & - & - & - & - \\
\hline & \multirow{4}{*}{ MP } & 1 & 0.80 & 0.60 & - & 0.75 & - & - & - & - & - & - & - & - & - & - \\
\hline & & 2 & 0.80 & 0.75 & - & 1.80 & - & - & - & - & - & - & - & - & - & - \\
\hline & & 3 & 0.80 & 0.70 & - & 1.55 & - & - & - & - & - & - & - & - & - & - \\
\hline & & 4 & 0.80 & 0.80 & - & 1.50 & - & - & - & - & - & - & - & - & - & - \\
\hline & MLN & - & - & - & - & - & 1 & 0.80 & 0.60 & 0.50 & 0.50 & - & - & - & - & - \\
\hline & MLS & - & - & - & - & - & 1 & 0.80 & 0.50 & - & 0.70 & - & - & - & - & - \\
\hline \multirow{5}{*}{2} & \multirow{3}{*}{$\mathrm{MF}$} & 1 & 0.80 & 0.50 & - & 1.30 & 1 & 0.80 & 0.30 & 0.15 & 0.70 & - & - & - & - & - \\
\hline & & - & - & - & - & - & 2 & 0.80 & 0.40 & - & 0.30 & - & - & - & - & - \\
\hline & & - & - & - & - & - & 3 & 0.80 & 0.35 & - & 0.20 & - & - & - & - & - \\
\hline & \multirow{2}{*}{$\mathrm{MP}$} & 1 & 1.00 & 0.40 & - & 0.80 & - & - & - & - & - & - & - & - & - & - \\
\hline & & 2 & 1.00 & 0.60 & - & 0.60 & - & - & - & - & - & - & - & - & - & - \\
\hline \multirow{3}{*}{3} & \multirow{2}{*}{ MF } & 1 & 1.00 & 0.67 & - & 0.35 & 1 & 0.90 & 0.48 & 0.30 & 0.60 & - & - & - & - & - \\
\hline & & - & - & - & - & - & 2 & 0.90 & 0.43 & 0.25 & 0.55 & - & - & - & - & - \\
\hline & MP & 1 & 1.00 & 0.35 & - & 0.50 & - & - & - & - & - & - & - & - & - & - \\
\hline 8 & \multirow{21}{*}{$\mathrm{MF}$} & 1 & 0.80 & 0.50 & - & 0.70 & - & - & - & - & - & - & - & - & - & - \\
\hline \multirow{2}{*}{9} & & 1 & 0.80 & 1.00 & - & 0.40 & - & - & - & - & - & - & - & - & - & - \\
\hline & & 1 & 0.80 & 0.80 & - & 1.60 & 1 & 0.80 & 0.25 & - & 0.45 & - & - & - & - & - \\
\hline 12 & & 1 & 0.80 & 0.50 & - & 0.80 & - & - & - & - & - & - & - & - & - & - \\
\hline \multirow{2}{*}{14} & & - & - & - & - & - & - & - & - & - & - & 1 & 0.65 & 0.41 & 0.46 & 0.43 \\
\hline & & - & - & - & - & - & - & - & - & - & - & 2 & 0.65 & 0.42 & 0.44 & 0.43 \\
\hline \multirow{2}{*}{15} & & - & - & - & - & - & - & - & - & - & - & 1 & 0.76 & 0.46 & - & 0.36 \\
\hline & & - & - & - & - & - & - & - & - & - & - & 2 & 0.76 & 0.46 & 0.38 & 0.43 \\
\hline 16 & & - & - & - & - & - & - & - & - & - & - & 1 & - & 0.48 & - & 0.10 \\
\hline 18 & & 1 & 0.50 & 0.55 & - & 1.20 & - & - & - & - & - & - & - & - & - & - \\
\hline 19 & & 1 & 1.00 & 0.45 & - & 0.70 & - & - & - & - & - & - & - & - & - & - \\
\hline 20 & & 1 & 0.60 & 0.70 & - & 0.80 & - & - & - & - & - & - & - & - & - & - \\
\hline 21 & & 1 & 0.60 & 0.60 & - & 0.50 & - & - & - & - & - & - & - & - & - & - \\
\hline 22 & & 1 & 0.60 & 1.00 & - & 0.20 & - & - & - & - & - & - & - & - & - & - \\
\hline 29 & & 1 & 0.60 & 0.70 & - & 0.50 & - & - & - & - & - & - & - & - & - & - \\
\hline 33 & & 1 & 0.70 & 0.70 & - & 1.50 & - & - & - & - & - & - & - & - & - & - \\
\hline 37 & & 1 & 0.60 & 0.60 & - & 1.30 & - & - & - & - & - & - & - & - & - & - \\
\hline 40 & & 1 & 0.70 & 0.80 & - & 1.30 & - & - & - & - & - & - & - & - & - & - \\
\hline 41 & & 1 & 0.70 & 0.80 & - & 0.20 & - & - & - & - & - & - & - & - & - & - \\
\hline 44 & & 1 & 0.60 & 0.70 & - & 1.70 & - & - & - & - & - & - & - & - & - & - \\
\hline 48 & & 1 & 0.80 & 1.10 & - & 1.20 & - & - & - & - & - & - & - & - & - & - \\
\hline $\mathrm{T}-03$ & MF & 1 & 0.80 & 0.50 & - & 0.70 & - & - & - & - & & - & - & - & - & - \\
\hline
\end{tabular}

Fuente. Elaboración propia. Leyenda: MF: Muro Frontal. MP: Muro Posterior. MLN: Muro Lateral Norte, MLS: Muro Lateral Sur, 2012. 
devenir Vol. 2, N³, ENERO- JUNIO 2015, PP. 79-98 - ESTUDIOS I ISSN 2312-7570

UNIVERSIDAD NACIONAL DE INGENIERÍ, LIMA

Figura 9. Corte y elevación del recinto 01 (R-01), Tipo 01.

Fuente. Tesis de Licenciatura Anli Chalco, 2012.

Figura 10. Qollqas de Pinkuylluna. Fuente. Tesis de Licenciatura Anli Chalco, 2012

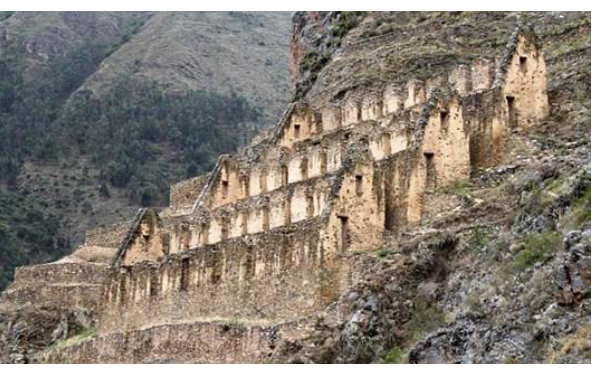

Figura 11. Qollqas de Machupicchu. Fuente. Tesis de Licenciatura Anli Chalco, 2012.

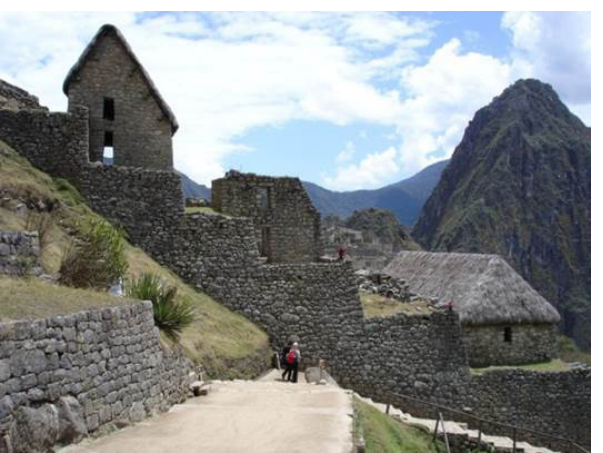

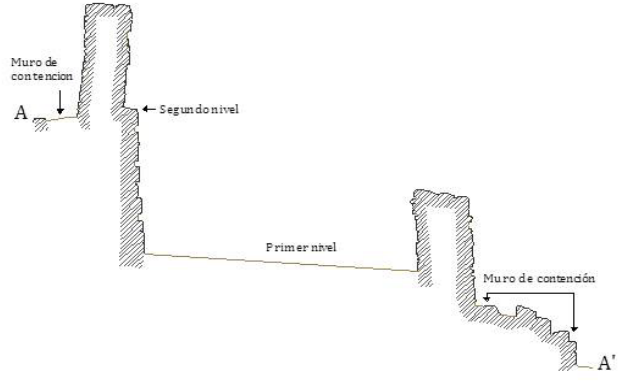

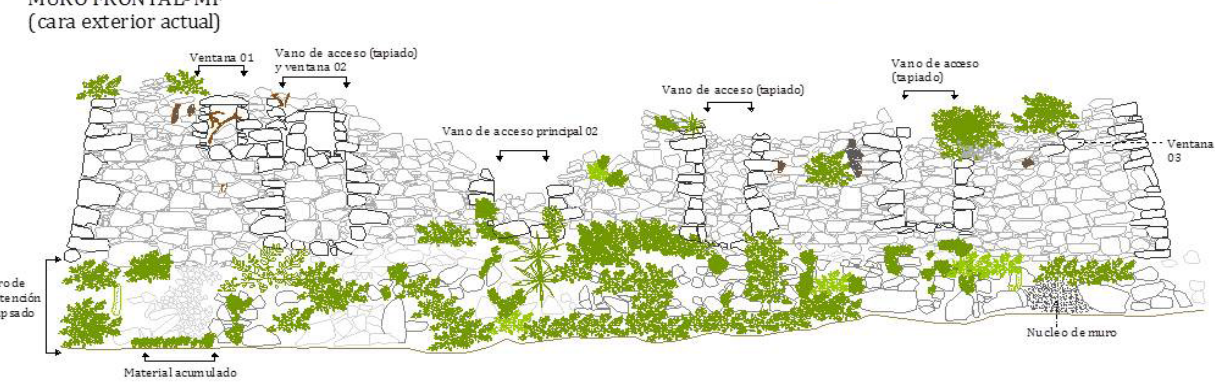

MURO POSTERIOR-MP (cara interior)

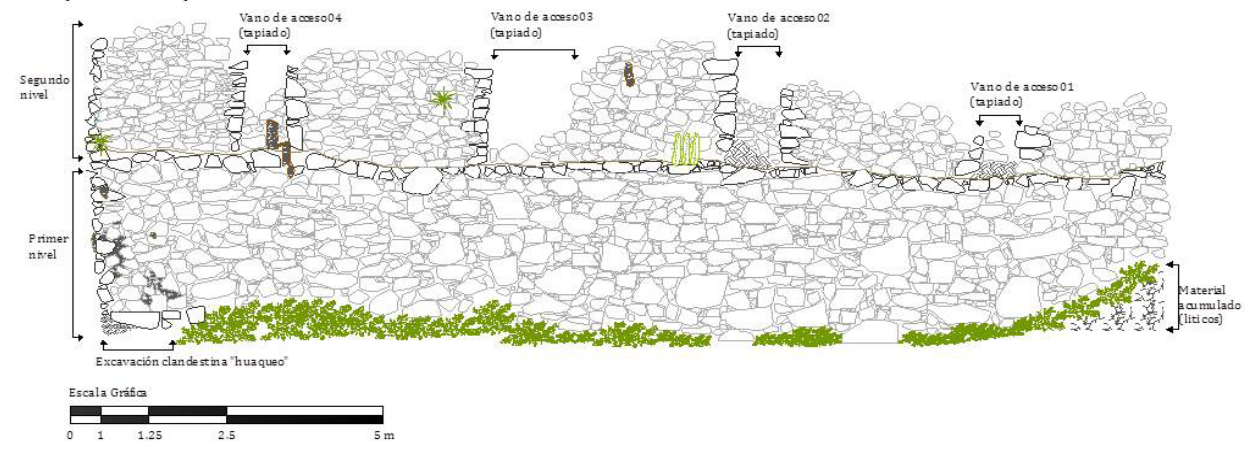

existentes en el cerro Pinkuylluna (Figura 10) y Machupicchu (Figura 11). Delante de los muros frontales y posteriores se registraron amplias plataformas, las que podrían haber sido tendales que servían para seleccionar y secar los productos, que luego eran guardados a través de los vanos de acceso. En cuanto se refiere al techo, estos fueron de dos aguas. Por estudio comparativo, es posible que en estas qollqas de dimensiones mayores se depositaran productos como la papa y el maíz, básicamente. Del mismo modo, es evidente que en algún momento hubo un incremento en la producción del alimento, lo cual hizo necesaria la construcción de más qollqas, para lo cual se aprovecharon los muros laterales de los recintos ya existentes, para adosar otras qollqas con las mismas características, pero con material lítico más rústico y acabados de menor calidad. También se registró posibles "restauraciones" hechas en la época inca, como es el caso del Recinto $1(\mathrm{R}-1)$, donde parte del muro lateral sur ha sido recompuesto y se nota la acción a manera de "parche".

Tipo 2. Es de planta cuadrangular de un solo nivel, con ductos de ventilación ubicados en la parte inferior del muro frontal orientados al N-E (Figura 12), con esquinas internas ovaladas y sin evidencia de vanos de acceso (Figura 13, Figura 14). Estos ductos de ventilación también sirvieron para extraer los productos almacenados y es probable que los productos fueran depositados por encima del muro posterior. Este segundo tipo de qollqa es muy parecido a otro tipo de almacenes de Pinkuylluna (Figura 15), donde se almacenaban papas. Por la dimensión de la qollqa es posible que el ambiente haya contado con cielo raso. 


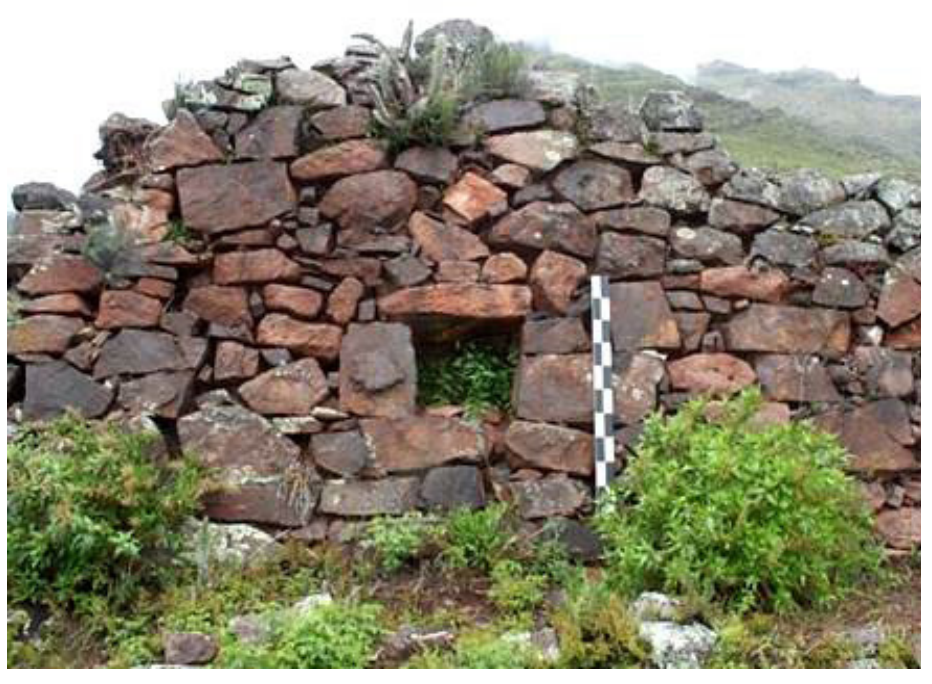

Esc: Gráfica

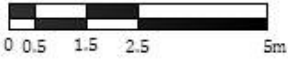

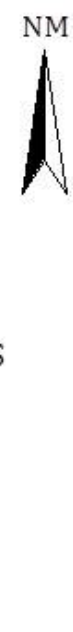

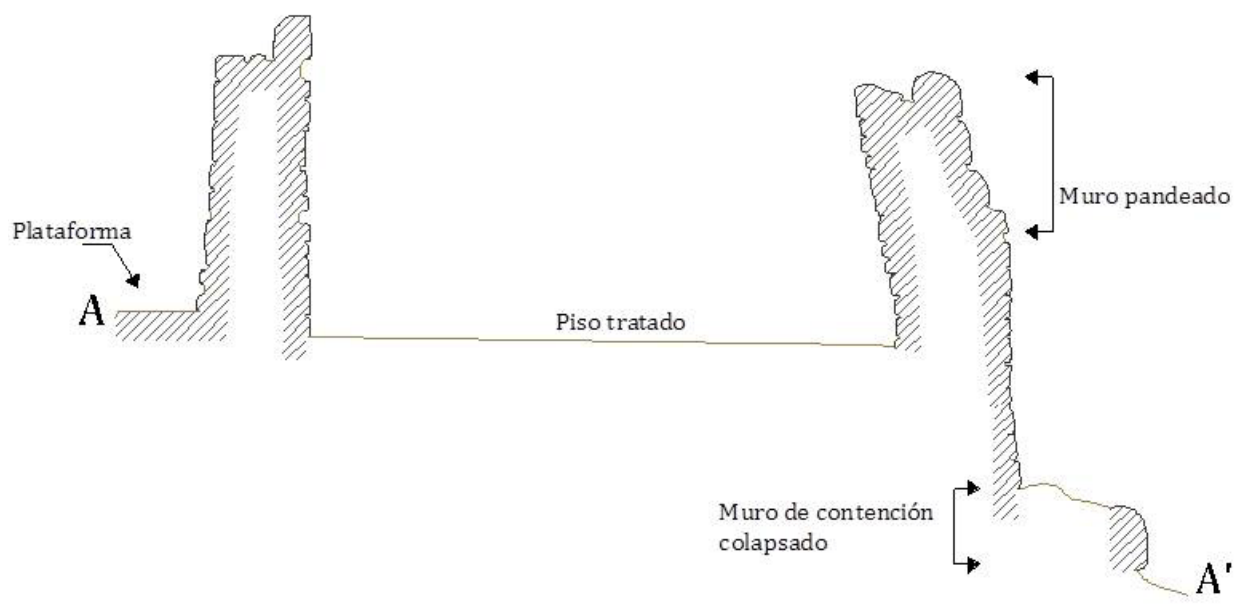

Figura 12. Ductos de ventilación del recinto 14 (R-14), Tipo 02.

Fuente. Tesis de Licenciatura Anli Chalco, 2012.

Figura 13. Plano de planta del recinto 14 (R-14), Tipo 02.

Fuente. Tesis de Licenciatura Anli Chalco, 2012.

Figura 14. Corte y elevación del recinto 14 (R-14), Tipo 02.

Fuente. Tesis de Licenciatura Anli Chalco, 2012

Figura 15. Qollqas de Pinkuylluna. Fuente. Tesis de Licenciatura Anli Chalco, 2012.

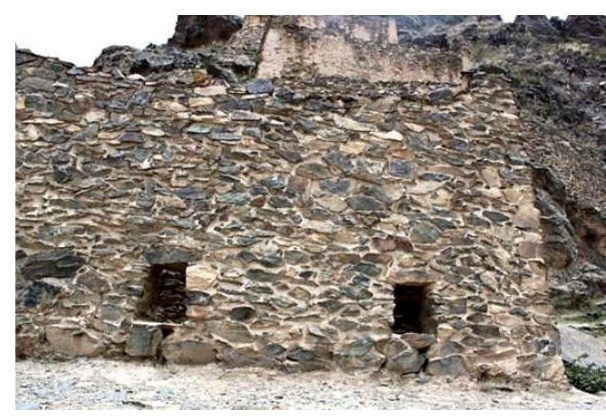


Figura 16. Plano de planta del recinto $17-19$ (R-17, R-19), Tipo 03.

Fuente. Tesis de Licenciatura Anli Chalco, 2012.
Tipo 3. Es de planta rectangular de un solo nivel, dividido por un muro medianero que forma dos ambientes, con vano de acceso de forma trapezoidal ubicado en el muro frontal (Figura 16). No se ha registrado ductos de ventilación. Por el material acumulado (piedras y tierra) existente al interior del recinto, producto del colapso de los muros, se puede deducir que probablemente se almacenaban productos de grano pequeño: “...ciertos productos, como la quinua, el tarhui y algunos tubérculos, habrían sido conservados en recipientes de cerámica y que ciertas estructuras podrían ser reconocidas como las destinadas a la conservación de alimentos..." (Ramírez, Ardido \& Samsonov, 2007, El sistema inca de almacenamiento de productos agrícolas, para. 3).

En algunos casos, al parecer, los recintos fueron viviendas, ya que se encuentran dispuestos alrededor de un patio central (R-40 y R-41), donde los vanos de acceso están ubicados en los muros laterales orientados hacia el N-O y S-E, además de estar asociados a material cultural mueble (fragmentos de cerámica y artefactos líticos). Otros recintos no fueron definidos por el mal estado de conservación en el que se encuentran y la excesiva vegetación presente en el sector.

De igual manera, se registraron 11 estructuras funerarias, que se identificaron en tres tipos:

Tipo 1. Chullpa de planta cuadrangular con techo abovedado y un vano de acceso orientado hacia la salida del sol (este).

Tipo 2. De planta circular delimitada por muros (registrado a nivel de piso).

Tipo 3. Tumbas en roca asociadas a recintos o, en otros casos, aisladas. El acceso se encuentra cerrado por un muro enlucido.

La estructura funeraria del Tipo 1 (Figura 17) se halla asentada sobre una plataforma poligonal (Figura 18), y un detalle muy relevante es que la cámara mortuoria presenta falsa bóveda, conformada por piedras de dimensiones pequeñas sin labrar. Esta característica arquitectónica en particular indicaría la influencia Huari en el sector:

...las falsas bóvedas de las culturas andinas son toscas y sin el menor intento de uniformar el acabado: colocaron las piedras en hiladas horizontales $y$, mediante su adelantamiento progresivo, iban reduciendo el diámetro que al final se cerraba con unas lajas de tamaño mayor. La falsa bóveda andina se utilizó siempre para cubrir reducidos espacios interiores y muy raramente su forma aparece en las fachadas. La conclusión más importante es que la falsa bóveda del área andina es muy anterior a la cultura de los inka. Hermann Trimborn ha investigado y señalado una gran variedad de construcciones con falsa bóveda existentes en la costa y en la sierra del Perú. El citado investigador insinúa la posibilidad de [...] considerar la falsa bóveda como un descubrimiento de los aimara [...] las construcciones con falsa bóveda que han recibido más atención son las chullpa, edificios de carácter funerario... (Gasparini \& Margolies, 1977, p. 157).
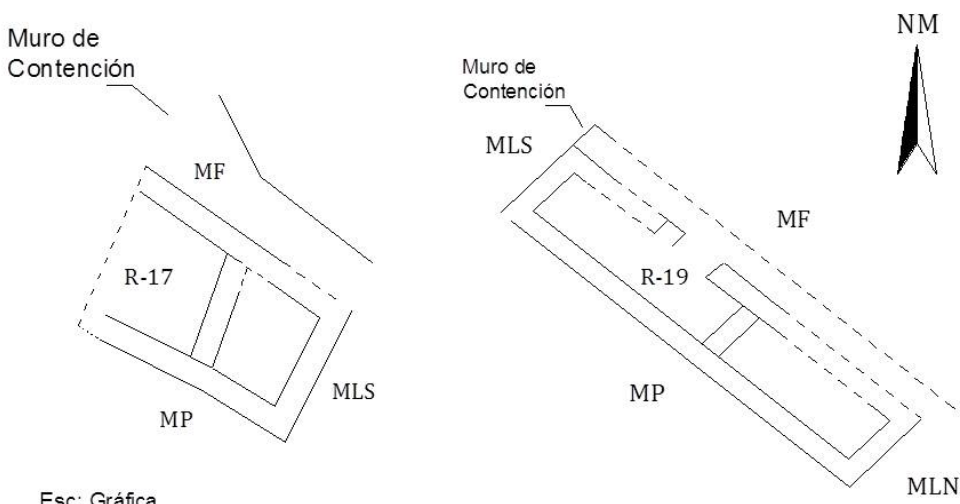


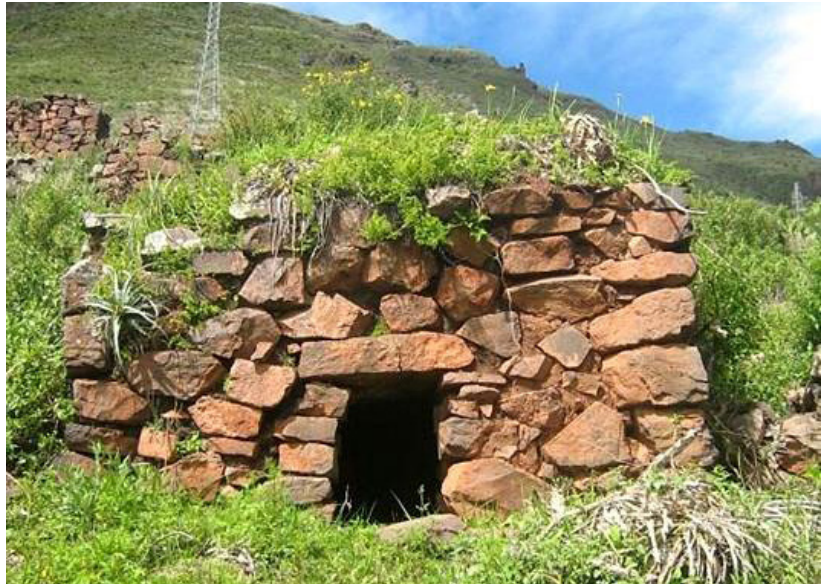

Otra característica arquitectónica importante es la presencia de una cornisa, ubicada entre la parte superior del muro y el inicio de la falsa bóveda, que sobresale unos $0.15 \mathrm{~m}$. Las esquinas interiores presentan amarres bien definidos, unidos con mortero de barro, y los muros al exterior de la estructura funeraria presentan sus niveles originales, con inclinación del $4 \%$. Asimismo, se encuentra un vano de acceso ubicado al medio del muro frontal, que es de forma trapezoidal, orientada hacia la salida del sol (este) (Figura 19), cuyo dintel actualmente se halla fragmentado con una grieta de 1 $\mathrm{cm}$. Al interior y exterior de la estructura funeraria se registraron pequeños fragmentos de enlucido de barro. El piso se halla descontextualizado a causa de las constantes excavaciones clandestinas y ofrendas a la Pacha Mama; así, se observó la presencia de basura contemporánea (palos, vidrios, plástico y bosta de ganado). No se encontró evidencia de material cultural en superficie (fragmentos de cerámica y artefactos líticos).

En cuanto al acceso, el sector Mauk'a Panteón está asociado al Qhapaq Ñan, camino al Antisuyo ${ }^{8}$, del cual se desprende un camino secundario en el sector Alabaduyoq. Este pasa por la parte baja del sector Mauk'a Panteón y del sector Llimp'ak Huanca, sigue su recorrido hacia una plataforma empedrada de forma semicircular denominada "era pata", continúa por el sector Huanca Qhaqhayoq y asciende de forma muy suave hacia la cumbre del cerro, en las alturas de la actual comunidad campesina Emiliano Huamantica de Huandar. En algunos tramos y escalinatas, el camino presenta calzada empedrada con muros laterales. En su recorrido, este camino conecta varios sistemas de andenerías. Otro camino que conecta a las qollqas se desprende de la parte baja del sector Mauk'a Panteón, es de trazo curvilíneo y asciende de forma muy suave por un extremo de todas las estructuras arquitectónicas con una orientación de E-O. Tiene una longitud de $210 \mathrm{~m}$ aproximadamente y un ancho promedio de $1.20 \mathrm{~m}$. Presenta calzada empedrada y tallado en roca. Entre los elementos arquitectónicos integrados al camino se registraron escalinatas y canales transversales. El material de construcción es piedra arenisca cuarzosa y, en algunos casos, canto rodado, unidos con mortero de calicanto ${ }^{10}$, lo que indicaría su reutilización en la época de la Colonia. El camino se encuentra delimitado por muros laterales, unidos con mortero de barro, de $0.40 \mathrm{~m}$ de ancho y una altura promedio de $0.80 \mathrm{~m}$.

8. La presencia del camino prehispánico al Antisuyo le da más realce e importancia al sistema de almacenaje:"...uno de los elementos diagnósticos más importantes para la determinación de un Camino Inka son los sitios arqueológicos que vincula..." (Vitry, 2004, p. 10).

9. De acuerdo a la información etnográfica, estas plataformas servían para secar y trillar los productos.

10. Cal y canto: "Se dice del aparejo de mampostería ordinaria unida con mortero de cal. Es vocablo usado generalmente en América Hispana" (Mesa, 1980, p. 22).
Figura 17. Estructura funeraria 03(T03) Tipo 01.

Fuente. Tesis de Licenciatura Anli Chalco, 2012.

Figura 18. Plano de planta de la estructura funeraria 03(T-03) Tipo 01.

Fuente. Tesis de Licenciatura Anli Chalco, 2012. 
devenir Vol. 2, N³, ENERO- JUNIO 2015, PP. 79-98 - ESTUDIOS I ISSN 2312-7570

UNIVERSIDAD NACIONAL DE INGENIERÍ, LIMA

Figura 19. Corte y elevación de la estructura funeraria 03(T-03) Tipo 01.

Fuente. Tesis de Licenciatura Anli

Chalco, 2012.
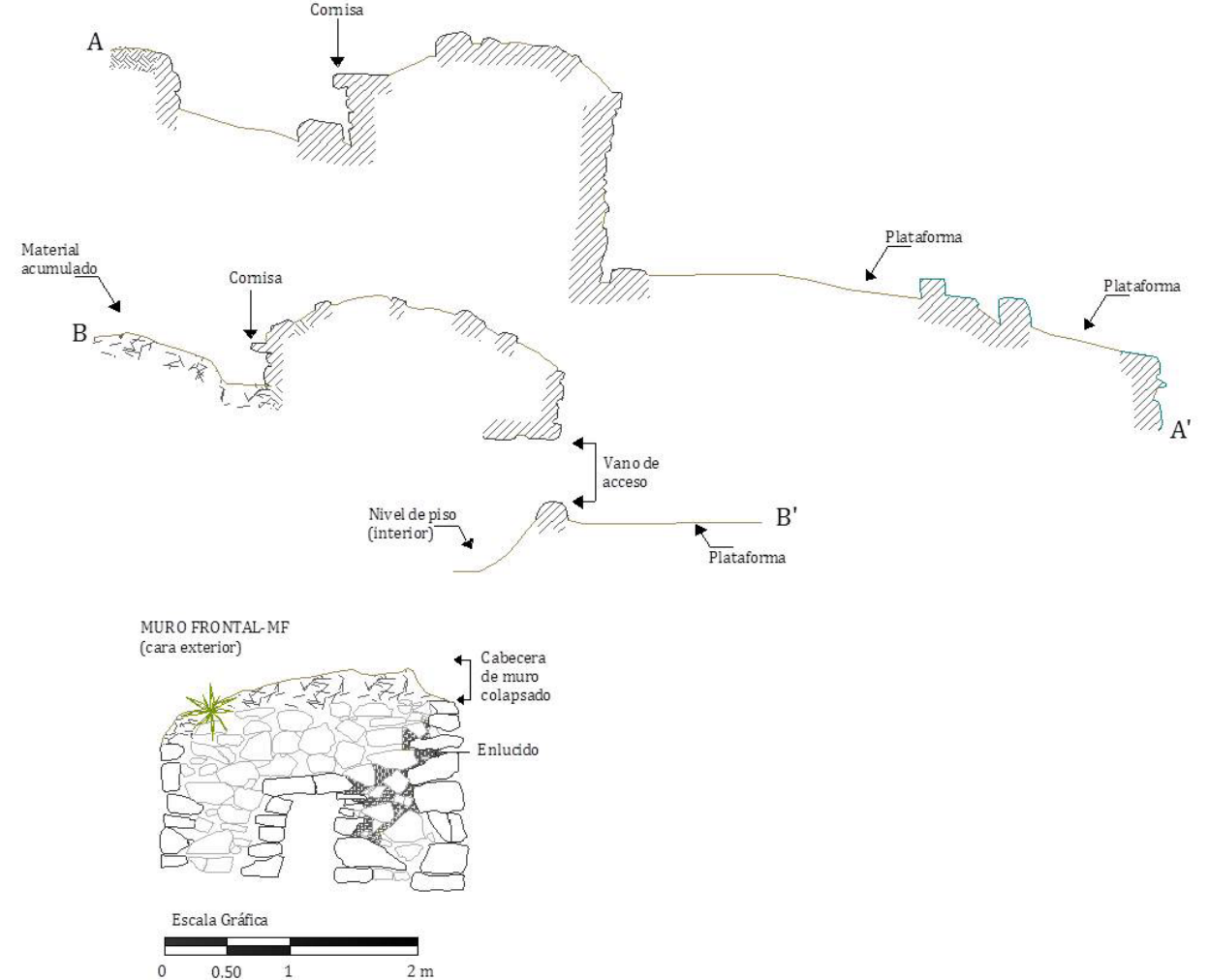

De igual manera, el aprovechamiento del agua para la agricultura fue vital. Los incas supieron aprovecharla captándola de las lagunas, ríos, arroyos, manantes, etc. por medio de un sistema avanzado de ingeniería hidráulica. Los canales de agua ubicados en el cerro Mama Ñusta transportaban el agua tomada desde la actual comunidad de Huancalle, a través de los sectores de Huayrancalle, Qhaqha Chimpa, Maso Huachana, Qori Pata, Qolqe Pata Calaberayoq, T'ankarniyoq, Mauk'a Panteón (parte superior e inferior), Herbanayoq, Huanca Qhaqhayoq, la comunidad campesina de Qosqo Ayllu y Huandar, hasta el límite distrital con San Salvador, donde confluyen en dos reservorios empedrados. Los muros de contención de ambos canales, de aparejo unido con mortero de barro, de tipo pirca armado en seco o, en algunos casos, tallados en la roca, tienen una leve inclinación de 4\%. El material de construcción es de arenisca cuarzosa y andesita. Estos muros de contención ayudaron a nivelar las zonas muy abruptas, formando un plano de apoyo. Ambos canales principales (superior e inferior) tienen un recorrido longitudinal paralelo de $4 \mathrm{~km}$ aproximadamente. De igual manera, se registraron canales secundarios que se desprenden de los dos canales principales, estos descienden en forma vertical y diagonal en dirección a los andenes. Los canales se acondicionaron al sistema de andenería, almacenaje y viviendas, con lo que se logró el desarrollo tecnológico que sustentó a parte del Imperio inca de entonces.

\section{Registro del Material Cultural Mueble}

Durante los trabajos de reconocimiento y prospección superficial, se registró material cultural mueble correspondiente a fragmentos de cerámica y artefactos líticos, ubicados especialmente en la parte inferior del sector Mauk'a Panteón. La mayoría son de tipo doméstico y presentan una variedad de formas como ollas, jarras, platos, escudillas y cuencos (Gráfico 1). Por su parte, los artefactos líticos corresponden a manos de mortero de uso doméstico (Tabla 4). Todo este material, en conjunto y en asociación con la arquitectura, implica actividades sociales en el escenario de un desarrollo cultural continuado. 


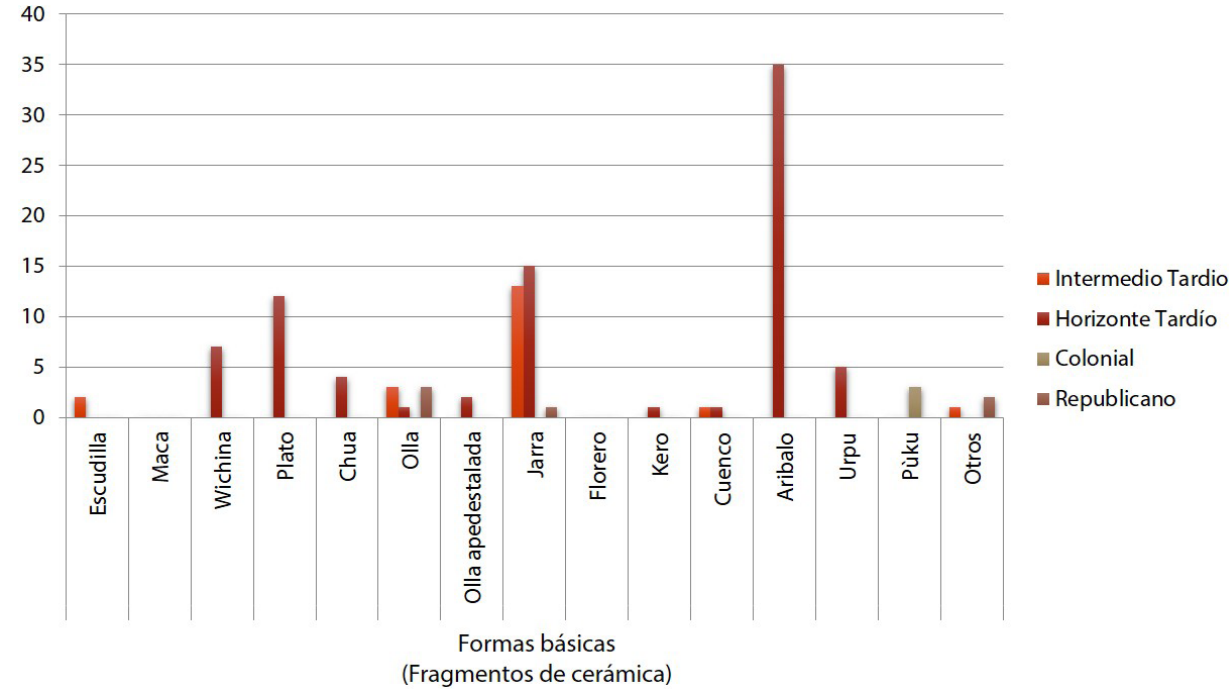

\section{Análisis Estructural}

Las construcciones prehispánicas fueron producto de una planificación que cumple con ciertos requisitos para la seguridad y durabilidad de sus obras como ubicación, distribución, resistencia, solidez y estabilidad. El diseño de las qollqas representa un desarrollo tecnológico adaptado al entorno, la configuración geográfica y las condiciones climáticas. La forma de los elementos arquitectónicos y su distribución sobre el espacio se manifiestan como medios para resolver problemas en respuesta a las condiciones de uso, funcionalidad e incluso de carácter simbólico, mediante el empleo de materiales adecuados en su construcción. Diferentes formas de construcción y tamaños, simetría, unidad y proporción en la distribución de los elementos arquitectónicos integrados (vanos de acceso, ventanas, muros de contención, etc) y espacios amplios para una ventilación adecuada son un reflejo de ello.

Las qollqas del sector Mauk'a Panteón están construidas sobre plataformas escalonadas, asentadas en una ladera muy pronunciada. En la época prehispánica se hicieron obras correctivas y de control de deslizamientos en laderas mediante la construcción de plataformas y grandes sistemas de andenería, en los cuales prima básicamente su función estructural.

Las qollqas se encuentran distribuidas en forma alineada y escalonada, construidas según la gradiente del terreno, separadas por calles, pasadizos y amplios espacios entre grupos de unidades de edificación, lo que permite el libre flujo de las corrientes de viento y de la luz solar. Están emplazadas sobre plataformas escalonadas con fuertes muros de contención, que otorgan mayor seguridad en casos de movimientos en masa, sismos o cualquier otra eventualidad natural o antrópica.

El $8^{\circ}$ Congreso Iberoamericano de Ingeniería Mecánica, sobre el diseño, fabricación y evaluación del prototipo de un sistema de almacenamiento, tuvo por finalidad analizar el funcionamiento del sistema de almacenes andinos o qollqas construidas en la región de la sierra peruana durante el periodo prehispánico. En dicho Congreso se concluyó que “...la mayoría de almacenes incas se encuentran por encima de los 3200 m.s.n.m..." (Ramírez, Ardido \& Samsonov, 2007, El sistema inca de almacenamiento de productos agrícolas, para. 1)

Efectivamente el sector Mauk'a Panteón se ubica sobre los 3000 m.s.n.m., y ofrece condiciones climáticas muy favorables para el almacenamiento de productos.
Gráfico 1. Cuantificación del material cultural mueble.

Fuente. Elaboración propia, Anli Chalco, 2012 
devenir Vol. 2, N³, ENERO- JUNIO 2015, PP. 79-98 - EsTUDIOS I ISSN 2312-7570

UNIVERSIDAD NACIONAL DE INGENIERÍ, LIMA

\begin{tabular}{ccc} 
Tabla 4. Artefactos líticos & & \\
\hline Nombre del objeto & Artefactos Líticos & \\
\hline Mano de mortero & Material & Morfología \\
Mano de mortero & Canto rodado & Cilindrico \\
Curpana (fragmentado) & & Esferico \\
Curpana (fragmentado) & Riolita & \\
\hline Curpana (fragmentado) & Canto rodado \\
\hline Alisador & Pizarra & \\
\hline Cuchillo & Cuarcita lechosa & \\
\hline Raspador & & \\
\hline Fuente. Tesis de Licenciatura Anli Chalco, 2012. &
\end{tabular}

Morris realizó excavaciones arqueológicas en las qollqas de Huánuco Pampa en el año 1985, evidenciando la existencia de ductos de ventilación “....al cual denomina 'suelo de ventilación'. A partir de esta evidencia discute sobre la posibilidad del empleo de sistemas de ventilación para lograr el tipo de almacenamiento necesario [...] donde su comprensión de variables ambientales habría permitido el diseño y construcción de un gran número de colcas..." (Ramírez, Ardido \& Samsonov, 2007, El sistema inca de almacenamiento de productos agrícolas, para. 2)

Haycochea, en 1994, realizó trabajos de investigación en depósitos ubicados en los valles tributarios del Urubamba, e hizo énfasis en la importancia de los sistemas de ventilación:

...como base del método para conservar los alimentos [...] el viento es generado por el movimiento de las masas de aire, las cuales se desplazan siguiendo el gradiente de presión atmosférica, de los núcleos de alta presión hacia los de baja presión [...] En las zonas de montaña se producen principalmente dos tipos de vientos locales: el viento catabático, el cual se produce cuando el aire frio y seco de las partes altas desciende hacia el fondo de un valle. Este movimiento de aire ocurre al anochecer, cuando la radiación solar cesa y el suelo del fondo del valle pierde el calor acumulado durante el día más rápido que el de las zonas más altas. El otro tipo de viento de denomina anabático, o viento del valle, el cual avanza en sentido inverso, es decir, asciende por las laderas durante el día, a medida que el sol calienta el suelo. Se trata de aire húmedo, el cual se enfría a medida que se eleva por la ladera. Como resultado de este proceso, se forman nubes de tipo lenticular en las partes altas de las montañas... (Ramírez, Ardido \& Samsonov, 2007, Comportamiento del viento en la región andina, para. 1)

La planificación de las qollqas resulta ser estratégica desde la ubicación altitudinal, en relación directa (en línea imaginaria) con la microcuenca del río Chongomayo y el abra de Manakauri, en dirección N-E, puerta de ingreso para las corrientes de viento que se encargan de darle las características climáticas propicias para la conservación de los productos. Las características estructurales de las qollqas permiten diferenciar el tipo de producto que se almacenaba en cada cual. Morris indica lo siguiente:

...el análisis de variables ambientales en los centros de almacenamiento incas indica que el diseño de las estructuras habría estado en función del comportamiento del viento local. En el caso de los almacenes para guardar alimentos, las estructuras con ventanas de ventilación orientadas hacia el valle podrían haber sido empleadas para almacenar papas y aquellas con ventanas orientadas hacia lo alto de la ladera habrían servido para guardar maíz. De acuerdo a los requerimientos de almacenamiento de papas, se puede indicar que las colcas para conservar los tubérculos frescos han debido emplear el efecto de los vientos de valle o anabáticos. En el caso del maíz, se habrían empleado los vientos de montaña o catabáticos, secos y fríos. (Ramírez, Ardido \& Samsonov, 2007, Conclusiones, para. 1). 
Los vanos de acceso, además de los ductos de ventilación, sirvieron de ventiladores, lo cual garantizaba la conservación de los productos. Este sistema de ventilación permite cambiar, renovar y eliminar el aire interior de las qollqas, para restituirlo por aire nuevo procedente del exterior. Para el Tipo 1 de qollqas, se debió construir ductos de ventilación más complejos y bien elaborados, que renueven el aire interno, a causa de su magnitud. En estas posiblemente se almacenaba gran cantidad de productos secos, como maíz (hipótesis que posteriormente será contrastada con futuras investigaciones arqueológicas con excavación). Algunos de los principios básicos para logar que dicha ventilación sea efectiva son la diferencia altitudinal, el grado de pendiente, la temperatura, la acción del viento, la radiación solar y la carga térmica.

Cabe mencionar que el sector Mauk'a Panteón se ubica en un valle sobre los 3000 m.s.n.m. y pertenece a la zona de vida Bosque Seco-Montano Bajo Subtropical' ${ }^{11}$ (bsMBS), donde las condiciones climáticas y el espacio geográfico muy accidentado, característico de la región Quechua ${ }^{12}$, generan fuertes corrientes de viento que vienen del $\mathrm{N}-\mathrm{E}$ con diferencias de temperatura, lo cual propicia un efectivo movimiento del aire.

En el interior del Recinto 1 (R-1) Tipo 1, hacia el ángulo S-O del punto de unión del muro posterior y el muro lateral sur, se registró una excavación clandestina muy profunda, en la cual se pudo observar el afloramiento rocoso y la cimentación. Entre el cimiento y el sobrecimiento se registró un lente de tierra de color blanco, dispuesto horizontalmente, de textura muy compacta, de $0.04 \mathrm{~m}$ de altura y $0.60 \mathrm{~m}$ de largo (medida referida a la dimensión de la excavación clandestina), lo que podría indicar un posible tratamiento de piso ${ }^{13}$ o la construcción de un falso piso, que actuaría como un elemento aislante del calor o el frío:"... La excavación de Huaycochea en Pumamarca demostró que los almacenes ubicados en este lugar habrían contado también con estos elementos aislantes, los que habrían facilitado la saturación del aire al interior del depósito..." (Ramírez, Ardido \& Samsonov, 2007, Análisis del prototipo de sistema, para. 13)

En el caso del Tipo 2, los ductos de ventilación están dirigidos hacia lo vientos locales, y también es posible que, debajo del material acumulado (tierra y piedras), exista un falso piso y que el ambiente haya presentado cielo raso, los cuales funcionaron como elementos aislantes en la conservación de los productos, especialmente de la papa:

El prototipo de almacén basado en tecnología andina fue diseñado en función de las características de los almacenes de Pumamarca y fue evaluado en condiciones controladas en el Campus de la P.U.C.P. Al analizarse el efecto del aislamiento producido por el cielo raso y el falso piso de material semipermeable a la humedad se observó que esta variable se elevaba de manera continua, con tendencia a la saturación. Este efecto permitiría conservar papas frescas. Se puede afirmar que los especialistas incas habrían logrado diseñar colcas capaces de almacenar tubérculos frescos en buenas condiciones por varios meses, sino años... (Ramírez, Ardido \& Samsonov, 2007, Conclusiones, para. 5)

11. "...Esta zona de vida está situada en la franja latitudinal subtropical, con una extensión de 154.36 Km² que representa el $3.03 \%$ de la superficie total del área de la provincia, geográficamente esta zona de vida ocupa los valles mesoandinos de la Cuenca del Vilcanota, comprende desde la confluencia del río Vilcanota con el río Huasacmayo, abarcando todo el curso hasta la quebrada Cancha Cancha. Dentro de esta zona de vida se encuentran los centros poblados de Taray, Huandar, Cuyo Chico, Pisac, [...] altitudinalmente se ubica entre los 2400 hasta cerca de los 3200 metros de altitud..." (Gobierno Regional Cusco, 2009, p. 67).

12. "La Región Quechua, Keswa, Quichua, Queshua o Quechua: se empleaban, en el Antiguo Perú, para designar las tierras del clima templado..." (Pulgar, 1978, p. 65). La región quechua para las sociedades prehispánicas fue de suma importancia, esta ofrecía las condiciones de vida apropiadas, por lo que se adecuaron a las características físicas y medioambientales.

13. Semejante a los tratamientos de piso que se hizo en la época huari, por ejemplo Pikillaqta. Lo que indicaría la presencia de la cultura huari. 
devenir Vol. 2, N³, ENERO- JUNIO 2015, PP. 79-98 - ESTUDIOS I ISSN 2312-7570

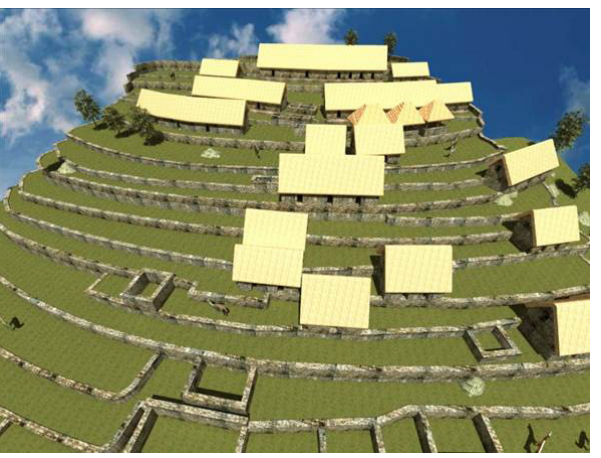

Figura 20. Reconstrucción hipotética del sector Mauk'a Panteón.

Fuente. Tesis de Licenciatura, Anli Chalco, 2012.

\begin{tabular}{|c|c|c|c|c|}
\hline \multicolumn{5}{|c|}{ Cuadro cronológico } \\
\hline \multicolumn{5}{|c|}{ Datación relativa para el sector Mauk'a Panteón y el área inmediata } \\
\hline Años & Cronología relativa & $\begin{array}{l}\text { Sector Mauk'a } \\
\text { Panteón }\end{array}$ & Área inmediata & Cerámica registrada \\
\hline $\begin{array}{l}1900 \\
1821\end{array}$ & Periodo Republicano & República & República & \\
\hline $\begin{array}{l}1800 \\
1532 \\
\end{array}$ & Periodo Colonial & Colonia & Colonia & \\
\hline \multirow[t]{2}{*}{1500} & \multirow{3}{*}{ Horizonte Tardío } & \multirow{3}{*}{ Inka Clásico } & Inka Imperial & \\
\hline & & & Inka Expansivo & \\
\hline 1200 & & & Inka Clásico & \\
\hline 1000 & \multirow{2}{*}{ Intermedio Tardío } & Killke & Killke & \\
\hline 900 & & Estilos Locales & Estilos Locales & \\
\hline \multirow{2}{*}{600} & \multirow{2}{*}{ Horizonte Medio } & \multirow{2}{*}{ Huari } & Lucre & \\
\hline & & & Huari & \\
\hline
\end{tabular}

Fuente. Elaboración propia Anli Chalco, 2012.

\section{Interpretación}

En el sector Mauk'a Panteón, se pudieron registrar varias modificaciones substanciales. Al parecer, en el Cerro Mama Ñusta en general, hubo una ocupación continuada, iniciada en la época del Intermedio Tardío (primera etapa), cuando construyeron los primeros andenes con plataformas y muros de contención, recuperando y adecuando espacios para la agricultura. Posteriormente, en el Horizonte Tardío (segunda etapa), se erigieron las qollqas para el almacén de los productos; se ampliaron las áreas de cultivo; se mejoró la infraestructura existente con la adecuación de un sistema hidráulico, (los canales ubicados en la parte superior del cerro), el cual servía para transportar y distribuir el agua a los diferentes sectores por medio de canales secundarios (diagonales y verticales); y se construyó una infraestructura vial que comunicaba los diferentes sectores ubicados en el área inmediata al sector Mauk'a Panteón. Más adelante, algunos vanos de acceso de los muros frontales de las qollqas fueron tapiados y se abrieron ventanas pequeñas en la parte superior de los mismos, lo que habría cambiado su función de un lugar de almacén a uno de vivienda, hecho que pudiera haberse dado durante la Colonia (tercera etapa). La definición de la función de los recintos y el tipo de producto almacenado en cada cual se determinó mediante estudios comparativos con los sistemas de almacenaje de Pinkuylluna y Machupicchu, donde las características constructivas (emplazamiento y disposición) son muy similares.

El material cultural mueble, registrado in situ en el sector Mauk'a Panteón, permitió establecer una cronología relativa, que podrá ser confirmada y ampliada por investigaciones futuras. Los fragmentos de cerámica y artefactos líticos también indican una ocupación continuada desde el Intermedio Tardío hasta la época republicana. Esta información es confirmada por el análisis arquitectónico, en vista de que evidencia tramos de muro de andén periodo del Intermedio Tardío, el cual corresponde a una primera ocupación (como ocurre en Ollantaytambo). Se elaboró una reconstrucción hipotética del sector Mauk'a Panteón (Figura 20), al igual que un cuadro hipotético de ocupación cultural (Tabla 5) para el mismo sector y el área inmediata, sobre la base del material cultural mueble (fragmentos de cerámica y artefactos líticos) y las características arquitectónicas de los recintos (qollqas y viviendas). 


\section{Estado de conservación}

Las estructuras existentes en el área de estudio se encuentran en un avanzado estado de deterioro, ante todo por el abandono de las entidades responsables de su salvaguarda.

Entre los diversos factores de deterioro que han iniciado los procesos que afectan su integridad, siendo los principales son de origen natural, como los factores abióticos y bióticos, las condiciones climáticas y/o el intemperismo, que están alterando el nivel horizontal y vertical de las estructuras en general. Asimismo, la fauna (presencia de ganado) y la flora (pastos, arbustos y vegetación invasiva) es causa de desintegración, inestabilidad estructural, deformaciones, salinización y acción de microorganismos. El otro agente de deterioro es el antrópico, por ejemplo, las actividades agrícolas, que causan cambios en el orden de los elementos líticos en zonas donde aún se encuentra evidencia. ${ }^{14}$

\section{Comentario}

El entorno natural y cultural alrededor del sector Mauk'a Panteón está siendo alterado y transformado. En la parte superior del mismo, se construyó dos torres eléctricas de alta tensión, que implicaron la apertura de nuevos accesos que terminaron por destruir algunos tramos de muro. Se necesitan trabajos urgentes de conservación y sensibilización, en razón de que este sitio arqueológico cumplió un rol muy importante como respuesta tecnológica muy bien planificada para el abastecimiento alimenticio en la época prehispánica.

\section{Referencias}

Angles, V. (2001). Písac y el Valle Sagrado de los Incas. (S. Angles, trad.) Lima, Perú: Industrial.

Bauer, B. (2008). Cusco antiguo, tierra natal de los Incas. (B. d. Centro de Estudios Regionales Andinos, Ed., \& J. Flores, trad.) Cusco, Perú: Centro de Estudios Regionales Andinos, Bartolome de las Casas.

Carreño, C. R. (2006). Diagnóstico de Peligros Geodinámicos en los Parques Arqueológicos de P'isaq y Ollantaytambo-Cusco. Boletin del Instituto Francés de Estudios Andinos. Vol. 35. (Número 2), 90-120.

Chalco, A. \& Valencia, E. (2012). Prospección arqueológica en el cerro Nustapata- Pisac- Provincia Calca. (Tesis de licenciatura). Universidad Nacional de San Antonio Abad del Cusco, UNSAAC., Cusco, Perú.

Covey, R. A. (2003). The Vilcanota Valley (Peru): Inka State Formation and the Evolution of Imperial Strategies. (Tesis de maestría/doctoral), University of Michigan, Michigan, EEUU.

Dirección Regional de Cultura Cusco DRCC. (2010). Camino principal al Antisuyo: Abra Qorao Qolquepata. Informe arqueológico.

Dirección Regional de Cultura Cusco DRCC. (2005). Plano catastral, mapa temático arqueológico del distrito de Pisac. (Plano catastral).

Domingo , I. \& Heather, B. (2007). Manual de campo del arqueólogo. Barcelona, España: Ariel

Garcia, S. L. (2005). Introducción al reconocimiento y análisis arqueológico del territorio. España: Ariel

Gasparini, G. \& Margolies, L. (1977). Arquitectura inka. Caracas, Venezuela: Facultad de Arquitectura y Urbanismo.

Gobierno Regional del Cusco. (2009). Diagnóstico y zonificación para el tratamiento de la demarcación territorial de la provincia de Calca (Vol. I).

Instituto Nacional de Cultura. (2004). Glosario de Términos Técnicos del Camino Andino.

14. Descripción hecha sobre la base de la ficha técnica de caminos del programa Qhapaq Ñan, Ex Dirección Regional de Cultura Cusco DRCC. 
devenir Vol. 2, N³, ENERO- JUNIO 2015, PP. 79-98 - ESTUDIOS I ISSN 2312-7570

UNIVERSIDAD NACIONAL DE INGENIERÍA, LIMA

Instituto Nacional de Cultura INC. (1983). Plano catastral del distrito de Pisac. (Plano catastral).

Instituto Nacional de Cultura INC. (2006-2007). Informe final de investigación arqueológica en el sector de Pinkuylluna del Parque Arqueológico de Ollantaytambo. (Informe arqueológico).

Kaulike, P., Kondo, R., Kusada, T. \& Zapata, J. (2003). Agua, Ancestros y Arqueología del Paisaje. Boletín de Arquelogía PUCP (7) 27-56.

Mesa, J. (1980). Glosario mínimo de términos de arquitectura virreynal (Segunda ed.). Cusco, Perú: Instituto Nacional de Cultura.

Pardo, L. (1957). Historia y arqueología del Cuzco (Vol. I). Lima, Perú: Impr. Colegio Militar Leoncio Prado.

Pulgar, V. J. (1987). Geografía del Perú: Las ocho regiones naturales (Novena ed.). Lima, Perú: Promoción Editorial Inca.

Ramirez, V., Ardido, G. \& Samsonov, V. (2007). Diseño, fabricación y evaluación del prototipo de un sistema de almacenamiento de productos agrícolas basado en el uso de energías renovables y tecnologia andina. $8^{\circ}$ Congreso Iberoamericano de Ingenieria Mecanica CIBIM8. Cusco, Pontificia Universidad Católica del Perú, Federación Iberoamericana de Ingeniería Mecánica.

Renfrew, C. \& Bahn, P. (1998). Arqueología teorías, métodos y prácticas. (Segunda ed.). Madrid, España: Akal.

Rostworowski, M. (2004). Historia el Tahuantinsuyu (Tercera ed.). (I. d. IEP., Ed.) Lima, Perú: PERUGRAPH

Vitry, C. (2004). Propuesta metodológica para el registro de caminos con componentes inkas. Salta, Argentina: Universidad Nacional de Salta Andes. 